\title{
FOUR-DIMENSIONAL CONSCIOUSNESS
}

\section{Richard Sieb}

\begin{abstract}
Conscious experience is the direct observation of conscious events. Human conscious experience is four-dimensional. Conscious events are linked (associated) by spacetime intervals to produce a coherent conscious experience. This explains why conscious experience appears to us the way it does. Conscious experience is an orientation in space and time, an understanding of the position of the observer in space and time. Causality, past-future relations, learning, memory, cognitive processing, and goal-directed actions all evolve from four-dimensional conscious experience. A neural correlate for four-dimensional conscious experience can be found in the human brain and is modelled by Einstein's special theory of relativity. The relativistic concept of spacetime interval is central for understanding conscious experience and cognition.
\end{abstract}

Key Words: conscious events, conscious experience, fourdimensional, relativity, spacetime interval

\section{Introduction}

The reticular activating system originates in the upper brainstem reticular core and projects through the intralaminar thalamic nuclei to the cerebral cortex to mediate arousal, attention, and consciousness, ie. the waking state (Evans,2003; Hannaman, 2005; Kinomura et al, 1996; Reiner, 1995; Sieb, 2013,2015; Steriade, 1995,1996; Young, 2009). Conscious experience makes up the content of consciousness, ie. what is in consciousness (Sieb,2004,2013,2015). Conscious experience is the direct observation of conscious events (Merriam-Webster). A conscious event consists of a set of qualia (qualities or properties perceived or experienced by the person-Oxford Dictionary). Each conscious event has a three-dimensional spatial position and extent in an experience. Each conscious event also has a temporal position in the experience, adding a dimension of time to conscious experience. In humans, knowing the world occurs through spatio-temporal experiences and interpretations (Maniadakis \& Trahanias,2011). 
The four-dimensional organization of conscious experience is readily apparent. Some conscious events making up an experience are observed simultaneously, but in different three-dimensional spatial positions; other conscious events are observed at the same spatial positions, but at different times. For example, when I examine my conscious experience of this room, many conscious events (door, window, light, light switch, walls, ceiling, floor, desk, chair, computer, monitor, keyboard, hands, mouse, etc.l are observed simultaneously, but in different three-dimensional spatial positions. These events are separated only by space (since they are observed at different spatial positions), but not by time (since they are observed simultaneously). I observe other conscious events (my finger and the start button on the computer, my hand and the mouse) at the same spatial positions (when I press the button or move the mouse), but at different times. These events are separated only by time (since they are observed at different times), but not by space (since they are observed at the same spatial positions). When I replace a glass with a cup, the two conscious events (glass and cup) occupy the same spatial position, but at different times. This also is separation only by time. Notice that the conscious events separated by time also have causeeffect and past-future relations. Separation in time gives rise to causality and past-future relationships. This organization is typical and characteristic of conscious experience and indicates that conscious experience is organized in space and time. Since there are three dimensions of space (length, width, height) and one dimension of time (Salgado,1995; Wikibooks link, 2014), conscious experience can be said to have four dimensions. We observe (experience) the world in four dimensions.

A dimension is extension in a particular direction; dimensions are the independent components of a coordinate grid system used to locate points or positions in a defined space (MerriamWebster). Space is the boundless three-dimensional extent in which events occur and have relative position and direction (any dictionary). Time is a continuum in which events succeed one another from past through present to future (any dictionary). space is often conceived in three linear dimensions, but modern physicists usually consider it with time, as part of a boundless four-dimensional continuum called spacetime. Spacetime is any 
mathematical model that combines space and time into a single continuum (Petkov,2010;Salgado,1995). Conscious experience is a spacetime continuum.

Many brain areas and multiple cognitive processes are involved in experiencing and processing time (Livesey, Wall \& Smith, 2007). Time plays an important role in the fusion of information throughout the cortex and the accomplishment of complex cognitive tasks (van Wassenhove, 2009); it binds our experiences, mental states, goals, and behaviors, significantly supporting our daily activities (Maniadakis \& Trahanias,2011). This is because spatial and temporal cognition implements a framework that enables the association of events (Maniadakis \& Trahanias, 2011). Immanuel Kant concluded that "space and time are not discovered by humans to be objective features of the world, but are part of an unavoidable systematic framework for organizing our experiences" (Lucas \& Hodgson,1985). Einstein's special theory of relativity is the most successful model of spacetime (Einstein,2001, other writings;Ellis \& Williams,2000; Salgado,1995; Wikibooks link,2014); in this model, space and time are part of a systematic framework for the association of events and the organization of experiences. Special relativity is a viable model for conscious experience.

\section{Special Theory of Relativity}

Einstein's special theory of relativity depends on frames of reference-observational perspectives of space described using coordinate systems (DiSalle,2009;Wikibooks link,2014). Two postulates form the basis of Einstein's special theory of relativity: (1) the laws of physics (in their simplest form) are invariant (identical) in all inertial frames of reference (frames of reference in uniform transitory motion), and (2) the speed of light is the same for all observers, regardless of the motion of the light source (DiSalle,2009; Einstein,2001, other writings). From these postulates was derived the "Lorentz Transformation", a mathematical expression by which the coordinates of one inertial frame of reference are transformed into the coordinates of another (Das,1993; DiSalle,2009; Einstein, 2001, subsequent writings; Salgado, 1995; Schutz, 1997; Wikibooks link, 2014). Special relativity describes how 
measurements of space and time by different observers are related.

Special relativity predicts a wide range of consequences (which have been experimentally verified). These include length contraction, time dilation, relativistic mass, mass-energy equivalence $\left(E=m c^{2}\right.$, where $c$ is the speed of light in a vacuum), a universal speed limit (c), and relativity of simultaneity (DiSalle,2009; Einstein,2001; Feynman, 1998; Roberts \& Schleif,2007; Salgado, 1995;Wikibooks link, 2014). Time dilates or lengthens (slows) and lengths contract (shorten) at higher speeds of a reference frame relative to another; this keeps the laws of physics invariant (postulate 1), c constant (postulate 2), and spacetime intervals invariant in the reference frames. In relativity, time cannot be separated from space, because the observed rate at which time passes depends on the relative velocity of the observer. Time and space are interwoven into a single continuum (the spacetime continuum). Special relativity has replaced the notion of an absolute universal time with the notion of time that is dependent on reference frame. Rather than an invariant (fixed) time interval between two events (as in classical physics), there is an invariant spacetime interval (Salgado, 1995; Wikibooks link, 2014). Special relativity is restricted to flat spacetime (Petkov,2010).

\section{General Relativity}

Einstein's general theory of relativity is a geometric theory of gravitation. General relativity is based on curved spacetime (DiSalle,2009). According to general relativity, gravity is not a force per se, as in Newtonian physics, but is the curvature of spacetime produced by the mass-energy contained in that spacetime (any physics text). At the core of general relativity are the Einstein Field Equations, which describe the relationship between the curvature of spacetime and the energymomentum contained in that spacetime (Wald,1984; any physics text). A body in free fall (not subject to any external forces, just gravity) actually moves with uniform motion in a curved trajectory. Free fall is equivalent to pure (inertial) motion within the curved geometry of spacetime (Poisson,2004). 
General relativity exhibits general covariance (its laws take on the same form in all frames of reference-Wald,1984). Hence general relativity satisfies the more basic principle of relativity (the laws of physics are the same for all observersGuilini,2006). Locally, the spacetime of general relativity is considered flat and the Einstein Equivalence Principle holds (the laws of special relativity are a good approximationGuilini,2006;Mermin,2005;Rindler,2001). A frame of reference that abides by the laws of special relativity can be defined at sufficiently small scales in the curved spacetime of general relativity. Conscious experience is such a frame of reference.

\section{Spacetime Intervals}

An event is the fundamental entity of observed physical reality represented by three coordinates of space and one coordinate of time in the spacetime continuum postulated by the theory of relativity (Merriam-Webster). A conscious event, considered in relativistic terms, is the fundamental entity of conscious observation represented by three coordinates of space and one coordinate of time in the spacetime continuum postulated for conscious experience. In relativistic physics, an event has a unique position specified by four coordinates. An example of the specification of the position of an event in classical relativistic physics is $(x, y, z, t)$. The unification of space and time is exemplified by the common practice of selecting a metric such that all four dimensions are measured in terms of units of distance $(x, y, z, c t)$, where "c" represents the speed of light in a vacuum and "ct" represents distance along the time axis (Petkov, 2010;Wikibooks link, 2014). Since $c$ is a universal constant equal to 1 , ct reduces to $t$. This metric enables mathematical description of spacetime, the positions of events in spacetime, and most importantly, spacetime intervals (Ellis \& Williams, 2000 ; Salgado, 1995).

In three-dimensional space, the separation between two objects is measured by the distance between them (the distance is purely spatial and always positive-Wikibooks link, 2014). In spacetime, the separation between two events is measured by the invariant spacetime interval between the events, which takes into account not only their spatial separation, but their temporal separation as well (Berry,1989; Ellis \& Williams,2000;Friedman, 2004;Morin, 
2007; Wikibooks link,2014). Spacetime interval may be formulated as follows (Petkov,2010;Wikibooks link, 2014): the spacetime interval "s" is equal to the difference between the space coordinates " $\Delta r$ " of two events minus the difference between the time coordinates " $c \Delta t$ " of the two events (in practice the square is utilized as the sign of the spacetime interval "s" is indefinite-positive, negative, or zero; $c$ is constant and equal to 1 ).

( spacetime interval) $s^{2}=\Delta r^{2}-c^{2} \Delta t^{2}$ or $s^{2}=\Delta r^{2}-\Delta t^{2}$, if $C=1$

\section{The Light Cone}

Spacetime intervals are defined by the light cone. A pulse of light emitted from a point spreads outwards in all directions at c. If light is confined to a two-dimensional plane, the light from a flash spreads out in a circle (Figs.1 and 2). If the growing circle is drawn with the vertical axis representing time (as in Figs.1 and 2), the result is a light cone (Penrose,2005; Salgado, 1995; Wikibooks link, 2014). In reality, there are three

\section{Fig. 1 Spacetime Intervals}

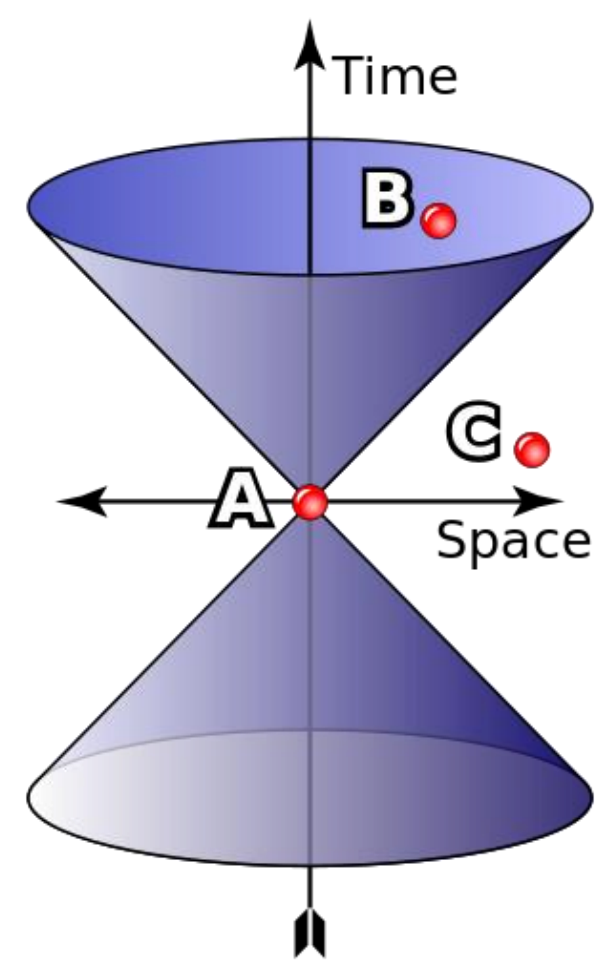




\section{Fig. 2 Past and Future Iight Cones}

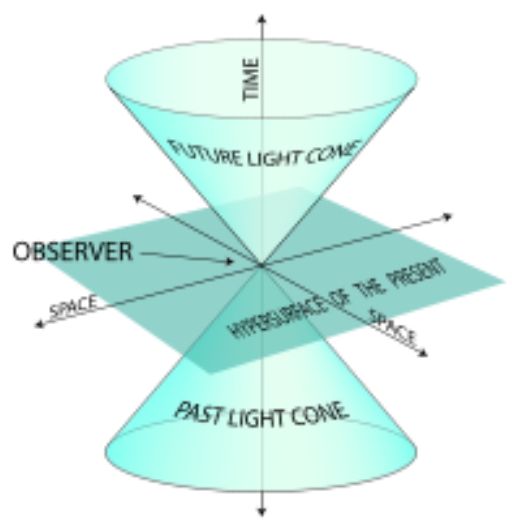

space dimensions, so light would actually form an expanding sphere and the light cone would be a 4D version of a cone (Salgado,1995). The concepts are easier to visualize with the number of space dimensions reduced to two. A light cone represents the path that a flash of light, emanating from a single event and travelling at the speed of light in all directions, would take through spacetime. Light cones are the same for all events and for all observers because $c$ is constant. Given an event $A$, all events that can be reached by a light pulse from A form a future light cone, while all events that can send a light pulse to A form an inverted past light cone (Figs.1 and 2).

\section{Light-Like Spacetime Intervals}

Two events on a light cone are separated at light speed. This separation is called a light-like spacetime interval (Wikibooks link, 2014). The difference in the space coordinates of two events on a light cone is exactly equal to the difference in the time coordinates of the events $\left(\Delta r^{2}=\Delta t^{2}, s^{2}=0\right.$, see Fig.1). There is a reference frame where events are separated at light speed (events occurring to a photon as it travels along its path). Such occurs when you directly observe a light source or any event (the event is visible because of reflected light).

\section{Time-Like Spacetime Intervals}

If the difference in the time coordinates of two events is greater than the difference in the space coordinates of the 
events $\left(\Delta t^{2}>\Delta r^{2}\right)$, the events fall inside a light cone (A and $\mathrm{B}$ in Fig.1) and the separation is called a time-like spacetime interval (Salgado,1995; Wikibooks link, 2014). There is a reference frame where two events with time-like separation may be observed at the same spatial position, but not at the same time (Berry,1989; Ellis \& Williams, 2000; Salgado, 1995; Petkov, 2010). The events may be observed at the same spatial position, but at different times (the events are separated only by time). Time-like spacetime intervals could account for the observation (experience) of conscious events at the same spatial positions, but at different times (this can occur only with time-like separation of the events).

\section{Space-Like Spacetime Intervals}

If the difference in the space coordinates of two events is greater than the difference in the time coordinates of the events $\left(\Delta r^{2}>\Delta t^{2}\right.$ ), the events fall outside a light cone ( $\mathrm{A}$ and $\mathrm{C}$ in Fig.1) and the separation is called a space-like spacetime interval (Wikibooks link, 2014). There is a reference frame where two events with space-like separation may be observed at the same time, but not at the same spatial position (Berry,1989; Ellis \& Williams,2000; Petkov, 2010). The events may be observed simultaneously, but at different spatial positions (the events are separated only by space). Space-like spacetime intervals could account for the observation (experience) of conscious events simultaneously, but at different spatial positions (this can occur only with space-like separation of the events).

\section{Organization of Conscious Experience}

Spacetime intervals account for the organization of conscious experience. Spacetime intervals in effect link (associate) conscious events to form a coherent four-dimensional conscious experience (ie. a coherent four-dimensional observation of conscious events). Spacetime intervals explain why conscious experience appears to us the way it does. Conscious experience is an orientation in space and time (an awareness of the existing situation with reference to space, time, and identityMerriam-Webster). It is an understanding of the position of the observer in space and time. A neural correlate for fourdimensional conscious experience based on spacetime intervals and modelled by Einstein's special theory of relativity has been found in the human brain. 


\section{Representation of Space}

In 1971, John O'Keefe discovered "place cells" in the hippocampus (O'Keefe,1976; O'Keefe \& Dostrovsky,1971). Place cells fire at particular places in a spatially-structured environment. They fire so reliably one can tell where an animal is in an environment by observing which neurons are firing. The hippocampus acts as a neural representation of the layout of an environment. A place cell fires when an animal passes through a specific small region of space called the place field. Place fields are considered allocentric rather than egocentric because they are defined with respect to the outside world, rather than the body. By orientation based on the environment, rather than the individual, place cells can work effectively as neural maps of the environment (Jeffery et al,2003). Place cells have been found in humans finding their way around a virtual reality town (Eckstrom et al,2003). The discovery of place cells led to a series of investigations that culminated in a book entitled "The Hippocampus as a Cognitive Map" which argued that the hippocampal neural network instantiates cognitive maps for spatial memory function (O'Keefe \& Nadel, 1978). This motivated hundreds of experimental studies aimed at clarifying the role of the hippocampus in spatial memory and spatial navigation (Maurer et al,2005; Moser \& Moser,1998; Quirk,1992). Spatial navigation involves the ability to orient oneself in space, to follow directions, and to recognize familiar places. It depends on the hippocampus. People have more active hippocampi when correctly navigating, as tested in computer-simulated "virtual" navigation tasks (Maguire et al,1998). The hippocampus is also involved in finding shortcuts and new routes between familiar places (Maguire et al,2000). This study showed that part of the hippocampus is larger in taxi drivers than in the general public and that more experienced drivers have bigger hippocampi. It is a frequent observation that, without a fully functional

hippocampus, humans may not remember where they have been or how to get where they are going. Getting lost is one of the most common symptoms of hippocampal damage (Chui et al,2004). An intact hippocampus is required for initial learning and retention in spatial memory tasks, in particular, ones that require finding the way to a hidden goal (Clarke et al,2005; Morris et al,1982; Sutherland, Kolb \& Whishaw, 1982; Sutherland et al,2001). There is an increase in firing patterns in the hippocampus in open environments and spatial learning and memory impairments after damage to the hippocampus (Binder,2009). The cognitive map hypothesis has been further advanced by recent discoveries of head direction cells, grid cells, and boundary cells in several parts of the brain that are strongly connected 
to the hippocampus (Moser, Kropff \& Moser,2008; Solstad et al, 2008). Place cells work with these other types of neurons (Muir \& Bilkey, 2001).

Place cell circuits are dynamic. They are constantly adjusting and remapping to suit the current environment. Place fields are roughly analogous to the receptive fields of sensory neurons in that firing corresponds to a representation of sensory information in the environment (Jones, 2013). However, place cells respond to complex stimuli rather than simple individual sensory cues (Jeffery et al,2003; Moser et al,2008). Sensory information is processed in various cortical structures upstream of the hippocampus before actually reaching the structure, so that the information received by place cells is a compilation of different stimuli (Jeffery et al,2003). The hippocampus receives highly processed sensory, emotional, and cognitive information from cortical association areas, the amygdaloid nuclei, the septal nuclei, the dentate gyrus, and other structures mostly via the entorhinal cortex (Carlson et al,1982; Flood \& Coleman, 1990;Goldman-Rakic,1990; Van Hoesen \& Hyman, 1990). Sensory information received by place cells can be metric or contextual (Jeffery,2007). Metric signals can be linear or directional. Directional inputs provide information about the orientation of a place field, whereas linear inputs essentially form a representational grid. The entorhinal cortex is the main input to the hippocampus and contains head direction cells and grid cells. Head direction neurons increase their firing rates above baseline levels only when the animal's head points in a specific direction. When stimulated these neurons fire at a steady rate (they do not show adaptation), but decrease back to their baseline rates, as the animal's head turns away from the preferred direction (usually about $45^{\circ}$ away from this direction-Taube, 2007). These cells are found in many brain areas, including the post-subiculum, retrosplenial cortex, thalamus (anterior and lateral dorsal thalamic nuclei), lateral mammillary nucleus, dorsal tegmental nucleus, striatum, and entorhinal cortex (Sargolini et al,2006). It seems probable that it is the head direction cell input that directs the orientation of place fields and the grid cells that direct the grid-like representation of place fields. Contextual cues allow established place fields to adapt to minor changes in the environment, such as a change in color, shape, or location. Metric corresponds to where place cells should fire while 
contextual corresponds to whether or not place cells should fire in a certain environment. Metric and contextual inputs are processed together in the entorhinal cortex before reaching the hippocampal place cells. Visual and olfactory inputs are examples of sensory inputs that are utilized by place cells (Save, Nerad \& Poucet,2000; Zhang \& Manahan-Vaughn, 2013). These can include both metric and contextual information (Jeffery, 2007). Spatial cues such as geometric boundaries or orienting landmarks are also important metric input (boundary or border cells are found in the entorhinal cortex and provide input to place cells). Movement can be an important metric cue called path integration (Moser et al,2008). Path integration is largely aided by grid cells, which establish a regular grid, so that during movement, place cells can fire according to a reference grid of their external environment (Jeffery, 2007). The existence of place cells shows how important the hippocampus is in spatial adaptation and spatial awareness.

Episodic memory is memory of personal past experiences of a particular time and place with reference to the person as a participant-observer (Munoz-Lopez, Mohedano-Moriano \& Insausti, 2010; Schacter, Gilbert \& Wegner,2011;Sieb,2015). Conscious recall is required to demonstrate episodic memory (Munez-Lopez, Mohedano-Moriano \& Insausti,2010;Tulving, 1983;Ullman, 2004). A fundamental feature of episodic memory is the spatial organization of events composing a unique experience. Considerable data indicate the hippocampus is critical to episodic memory in humans (Rolls,2013; Sieb, 2015; Steinvorth, Levine \& Corkin,2005;Vargha-Khadem et al,1997). An allocentric representation of the environment is encoded in the hippocampus and stored as episodic memory (Ono et al,1993; Serino \& Riva, 2014). Neurons in the CA3 region of the hippocampus, receiving inputs from the entorhinal cortex, form an allocentric viewpoint dependent representation; whereas neurons in the CA1 region of the hippocampus, receiving inputs from CA3 Schaffer collaterals, rapidly encode an allocentric view-point independent representation (Robertson, Rolls \& Georges-Francois, 1998;Rolls, 2007). It is possible to distinguish between the allocentric representation formed by CA3 and the allocentric representation formed by CA1 (Behrendt,2013). Hippocampal place cells play a crucial role in the establishment and maintenance of both representations (Serino \& Riva,2014). The encoding of activity of both the CA3 and CA1 regions in sync is necessary for the encoding of a coherent short term episodic memory (Serino \& Riva, 2014). This suggests that the CA3 encodes events 
and the CAl encodes spacetime interval relations (the latter organize a coherent experience). Episodic memory is a combination of information from different sensory modalities and the bulk of incoming information to the hippocampus originates from polymodal areas of the neocortex (Mohedano-Moriano et al, 2007). Episodic memory is based on context and its retrieval often depends on context. Place cells prime memory by differentiating the context (Smith \& Mizumori,2006). Hippocampal place cells play a critical role in retrieving a coherent episodic memory because of the reciprocal connectivity between the hippocampus and neocortical regions. When prompted by a retrieval cue, the full episodic memory can be retrieved through the process of pattern completion (Burgess et al,2001; Byrne, Becker \& Burgess, 2007). Episodic recall (including simulation of future or imaginary events) may be traceable to retrieval cues (encoded in neocortical areas and introduced to the hippocampus via the entorhinal cortex) inducing the reinstatement of neuronal assemblies in CA3 and CA1 (Serino \& Riva, 2014). Specific place cells begin firing when exposed to signals or a subset of signals from a previous location (Nakazawa et al,2004). Hippocampal place cells have been shown to exhibit stable firing patterns even when cues from a location are removed-they complete memory patterns (Rolls, 2013). Furthermore, place cells can maintain representation of one location while recalling the neural map of a separate location, effectively differentiating between present and past experienceplace cells demonstrate both pattern completion and pattern separation (Smith \& Mizumori,2006). Place cells often exhibit reactivation outside their place fields-this has a much faster time scale than the actual experience and occurs mostly in the same order in which it was originally experienced, or more rarely, in reverse. This replay is believed to have a functional role in memory retrieval and memory consolidation (Mozer et al,2008;Rolls,2013). It was also shown that the same sequence of activity may occur before the actual experience-this preplay may have a role in prediction and learning. Serino and Riva (2014) found that for effective episodic memory retrieval, it is crucial that the representation in CA1 be synced with the representation in CA3. In Alzheimer's disease, a break in the "mental frame syncing" between the two representations may occur, caused by damage to the hippocampus, and may contribute significantly to the early impairment of memory (Serino \& Riva, 2014). Place cells are part of a complex circuit that informs memory and awareness (Jeffery, 2007; Jeffery et al, 2003).

\section{Representation of Time}


Another fundamental feature of episodic memory is the temporal organization of serial events that compose a unique experience (Tulving,1972,1983). The hippocampus is essential to

remembering unique sequences of events as well as disambiguating sequences that share common events (Brown et al,2010; Kumaran \& Maguire, 2006; Lehn et al,2009;Ross, Brown \& Stern,2009;Tubridy \& Davachi, 2011). Studies on humans (Hales et al,2009; Hales \& Brewer,2010; MacDonald et al,2011; Staresina \& Davachi,2009) have shown that the hippocampus is critical to remembering the flow of events in distinct experiences and, in doing so, bridges temporal gaps between non-contiguous events. There is a robust hippocampal representation of sequence memories, highlighted by "time cells", that encode successive moments during empty temporal gaps between key events, while also encoding location and ongoing behavior (MacDonald et al,2011).

\section{Representation of Spacetime}

The hippocampal representation of time is quite similar to its representation of space (MacDonald et al,2011): a large proportion of neurons are engaged in both (Muller,1996; Thompson \& Best, 1989); time cells fire at discrete moments during "empty" periods in a temporally-organized memory, much as place cells fire at discrete locations, devoid of specific stimuli (Muller, 1996); time cells signal the nature and timing of salient events, just as place cells signal the nature and spatial location of salient events (Komorowski, Manns \& Eichenbaum,2009; Manns \& Eichenbaum,2009); time cells disambiguate overlapping sequence memories, just as place cells disambiguate overlapping routes (Ferbinteanu \& Shapiro,2003; Frank, Brown \& Wilson,2000; Wood et al,2000); and time cells partially "retime" when key temporal parameters are altered, just as place cells partially "remap" when critical spatial cues are altered (Muller \& Kubie, 1987). These findings suggest that hippocampal neuronal ensembles segment temporally-organized memories much as they segment spatial memories (MacDonald et al,2011). MacDonald and coworkers (2011) conclude that place cells and time cells reflect fundamental mechanisms by which hippocampal neural networks parse any spatiotemporal context into quantal units of where and when important events occur and bridge, and thereby organize elements, in a conceptual organization of events. Eichenbaum (2014) concludes that the firing properties of time 
cells parallel the properties of place cells and provide an additional dimension that is integrated with the spatial

dimensions. These investigators conclude that hippocampal neurons differentially encode key events in space and time and compose unique spatially and temporally-organized representations of specific experiences. The representation of time and space in the hippocampus is a fundamental mechanism for organizing the elements of experience.

\section{Representation of Spacetime Intervals}

In 2014, John O'Keefe, May-Britt Moser, and Edvard Moser were awarded the Nobel Prize in Physiology or Medicine for the discovery of grid cells, cells that constitute a "positioning system" in the brain. A grid cell is a type of neuron found in the brains of many species that allows them to understand their position in space (Doeller, Barry \& Burgess,2010; Fyhn et al, 2008; Hafting et al,2005; Jacobs et al,2013;Killian, Jutras \& Buffalo,2012; Yartsev, Witter \& Ulanovsky,2011). Grid cells have been identified in rats, bats, monkeys, and humans. A grid cell

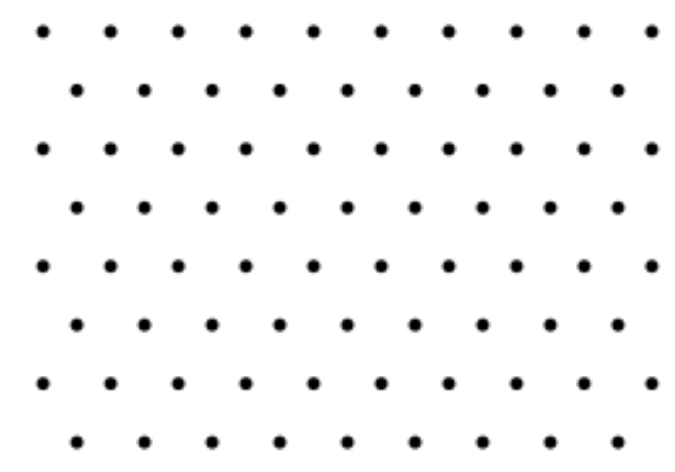

\section{A hexagonal lattice. The dots are firing fields of a grid cell.}

fires when a freely-moving animal traverses a set of small regions (firing fields) roughly equal in size and arranged in a periodic triangular array that covers the entire available environment (Hafting et al,2005). Firing fields are equally spaced apart, such that the distance from one firing field to all six adjacent firing fields is approximately the same (when an environment is resized, the field spacing may shrink or expand differently in different directions-Barry et al,2006). Firing fields are positioned such that the six neighboring fields are located at approximately 60 degree increments (firing fields are organized into a hexagonal lattice, above figure). 
Because the entorhinal cortex provides by far the largest input to the hippocampus, it is clearly important to understand the firing properties of entorhinal cortex neurons. Grid cells that lie next to one another (recorded from the same electrode) usually show the same grid spacing and orientation, but their grid vertices are displaced from one another by apparently random offsets. Cells recorded from separate electrodes at a distance from one another, however, frequently show different grid spacing. Cells that are located more ventrally in the medial entorhinal cortex generally have larger firing fields at each grid vertex and correspondingly greater spacing between the grid vertices (Hafting et al,2005). Grid cell activity does not require visual input, since grid patterns remain unchanged when all lights are extinguished. When visual cues are present, they exert strong control over the alignment of the grids. Grid patterns appear on the first entrance of an animal into a novel environment and usually remain stable thereafter. When an animal is moved into a completely different environment, grid cells maintain their grid spacing and the grids of neighboring cells maintain their relative offsets (Hafting et al,2005). Hafting suggests that a cognitive representation of Euclidean space is computed in the entorhinal cortex and fed into the hippocampus for the formation of memories.

Killian and coworkers (2012) identified individual neurons in the primate entorhinal cortex that fired when an immobile monkey fixated multiple discrete locations in the visual field in each of many sequentially presented complex images. These firing fields possessed spatial periodicity similar to a triangular tiling with a corresponding well-defined hexagonal structure. Killian concluded that entorhinal neurons encode space during visual exploration, even without locomotion, and that these grid-like spatial representations may anchor the encoding of stimulus content in a complex visual scene. Jacobs and coworkers (2013) recorded neuronal activity from neurosurgical patients performing a virtual-navigation task and identified cells exhibiting grid-like spiking patterns. Doeller and coworkers (2010) provided the first evidence for grid-cell-like representations in humans that implicates a network of regions supporting spatial cognition and autobiographical (episodic) memory. This network consisted of the entorhinal/subicular, posterior and medial parietal, lateral temporal, and medial 
prefrontal cortical areas. The signal was greatest in the right entorhinal cortex. Doeller concluded that grid cells provide a strikingly periodic representation which is suggestive of very specific computational mechanisms.

The entorhinal cortex has reciprocal connections with the hippocampus and many other brain areas (Serino \& Riva, 2014). The superficial layers of the entorhinal cortex provide most of the input to the hippocampus, while the deeper layers receive the most output from the hippocampus. A number of other connections are important in hippocampal function (Amaral \& Lavenex, 2006). Besides output to the entorhinal cortex, additional output goes to other cortical areas, including the prefrontal cortex (PFC), posterior parietal cortex (PPC), the lateral septal area, and the mammillary body. A key function of PPC is the implementation of visuospatial attention (Hopfinger et al,2001; Mesulam,1981; Wager, Jonides \& Reading,2004; Wendelken, 2015) and of spatial processing in general (Amorapanth, Widick \& Chatterjee,2010; Husain \& Nachev,2007;Marshall \& Fink,2001;Sack, 2009). The intraparietal sulcus (IPS), which separates the inferior and superior parietal lobes (IPL, SPL), has been shown to contribute to the maintenance of spatial location information (Ackerman \& Courtney,2012;Todd \& Marois,2004;Xu \& Chun,2006) and the IPL is a locus of spatial-relational processing (Ackerman \& Courtney, 2012). Wendelken and coworkers (2012) observed selectivity for higher-order visuospatial processing in right PPC. These brain areas have also been implicated in timeexperiencing: the cerebellum, right $\mathrm{PPC}$, right $\mathrm{PFC}$, frontostriatal circuits, and insular cortex for duration perception (Bueti, Bahrami \& Walsh,2008;Hinton \& Meck,2004;Ivry \& Schlerf, 2008; Lewis \& Miall,2003; Wittmann,2009); the inferior frontal and superior temporal lobes, hippocampus, medial PFC, medial parietal and posterior cingulate cortex for past-future distinction and mental time travel (Botzung, Denkova \& Manning, 2008; Suddendorf, Addis \& Corballis,2009;Viard et al,2011); the PFC, IPC, superior colliculus, and insular cortex for synchronous and asynchronous event distinction (Dhamala et al, 2007; Kavounoudias et al,2008); and the posterior sylvian regions, $\mathrm{PPC}$, and temporo-parietal networks for temporal order judgment (Bernasconi et al,2010;Kimura et al,2010;Woo, Kim \& Lee, 2009). Wendelken and coworkers (2012) observed stronger PPC activation for processing inequalities, than for processing 
equalities, and argued that this was due to representation of the more specific inequality relationships in PPC. This is interesting because space-like and time-like spacetime intervals are inequalities. Wendelken (2015) found that current evidence is most consistent with accounts that involve estimation and probabilistic computation for the PPC. PPC is a primary contributor to mathematical (numerical) cognition (Dehaene et al,2003; Rosenberg-Lee et al,2011). Evidence from a large-scale meta-analysis indicated clearly that the pattern of activation of PPC is associated most closely to mathematical cognition (Wendelken,2015). There is an independent core numerical system localized to the IPS (Cohen Kadosh et al,2005; Dehaene et al, 2003;Nieder, Diester \& Tudusciuc,2006). Human neuroimaging studies have demonstrated that regions of the parietal lobe, including the IPS and IPL, activated when subjects are asked to perform calculation tasks. Dehaene and colleagues suggested that these parietal structures play complementary roles. The IPS is thought to house the circuitry that is fundamentally involved in numerical estimation (Piazza et al,2004), number comparison (Pinel et al,2001;Pinel et al,2004) and on-line calculation, while the IPL is thought to be involved in overlearned tasks, such as multiplication (Dehaene,1997). In addition to these parietal regions, regions of the frontal lobe are also active in calculation tasks. In monkeys, neurons have been found in the frontal cortex and in the IPL that respond to numbers (Nieder,2005; Nieder, Freedman \& Miller,2002; Nieder \& Miller,2004). There is evidence that numerical cognition is intimately related to spatial cognition (Dehaene, 1992; Hubbard et al,2005). Regions of the parietal cortex show shared activation for both spatial and numerical processing (Dehaene, 1992), and as described previously, for temporal processing. These various lines of research suggest a strong, but flexible, connection between numerical, spatial, and temporal cognition in PPC and PFC. This is what might be expected if the PPC and PFC processed spacetime interval inequalities. Wendelken and Bunge (2010) found that the extraction of mental relations from the hippocampus by the PPC and PFC initiates an important process of relational integration. These studies support the contention that entorhinal cortex grid cells provide a reference grid in the hippocampus for the representation of spacetime interval 
inequalities and that the PPC and PFC may preferentially extract these in a process of relational integration.

\section{Causality}

Because signals and other causal influences cannot travel faster than the speed of light, light cones (Figs.1 and 2) define the concept of causality (Einstein,2001, other writings; Penrose, 2005; Salgado,1995). For time-like spacetime intervals (inside light cones), there is enough time between the events that signals or information can travel between the events at less than the speed of light (Einstein,2001, other writings; Penrose,2005; Salgado, 1995). Hence one event can influence or be influenced by the other event, by signals or information that does not need to travel faster than the speed of light. One event could be the cause or effect of the other event. If B causes A, B exists in the past history (in the past light cone) of A (Figs.1 and 2). If $B$ is caused by A, B exists in the future (in the future light cone) of A (Figs.1 and 2). The past light cone of an event represents the boundary of its causal past and the future light cone the boundary of its causal future. Events with time-like spacetime interval separation may be said to have a past or future relation.

When a space-like spacetime interval separates two events (outside light cones), not enough time passes between their occurrences for there to exist a cause-effect relationship crossing the spatial distance between the events at the speed of light or slower (Einstein,2001, other writings; Penrose, 2005; Salgado,1995). Generally, the events are considered not to have a past-future relation.

Causality is distinct from mere contingency or covariation (Cummins, 2014). In causality, one event has the power to bring about another event. In covariation and contingency, two events are simply statistically dependent on one another (Cheng,1997; Pearl,2000). Neuro-imaging studies show that the brain distinguishes causal events from non-causal events (Cummins, 2014). There are significantly higher relative levels of activation in the right middle frontal gyrus and the right IPL for causal relative to non-causal events (Fugelsang et al,2005). Causal judgments, beyond associative judgments, generated 
distinct activation in left dorsolateral PFC and right precuneus (part of the SPL), substantiating the particular involvement of these areas in assessments of causality (Parris et al,2009; Satpute et al,2005). Perceptual causality can be distinguished from inferential causality (Cummins,2014). Inferential causality activates the medial frontal cortex (Fonlupt,2003), with particular left hemispheric involvement (Roser et al,2005). Perceptual causality activates the right parietal lobe suggesting that the right parietal lobe is involved in the processing of the spatial attributes of causality (Straube \& Chatterjee,2010; Straube, Wolk \& Chatterjee,2011). The PPC and PFC therefore appear to be involved in the assessment of causality. Since they also appear to be involved in the processing of spacetime interval inequalities, assessments of causality could arise in relation to the processing of time-like spacetime intervals by the PPC and PFC. This supports the contention that spacetime interval inequalities are represented in the hippocampus and extracted by the PPC and PFC for relational integration.

\section{Causality, Perception, and Cognition}

Causal plausibility has an impact on behavioral judgments and neural processing (Cummins, 2014). Areas associated with learning and memory (caudate, parahippocampal gyrus) were activated when data and theory were consistent (plausible + strong data OR implausible + weak data). When data and theory were inconsistent (implausible + strong data OR plausible + weak data), attention and executive processing areas were active (anterior cingulate cortex, PFC, precuneus). Attention and executive processing areas were particularly active when plausible theories encountered disconfirming (weak) data. Different types of knowledge are activated when reasoning from cause to effect than when reasoning from effect to cause (Cummins, 2014). When reasoning from cause to effect, disablers (preventive causes) are spontaneously activated; when reasoning from effect to cause, alternative causes are spontaneously activated (Cummins et al,1991;Cummins,1995,1997; De Neys, 
Schaeken \& d'Ydewalle,2002,2003; Janveau-Brennan \& Markovits, 1999;Markovits et al,1998;Vershueren et al,2004).

Perception is the identification, organization, and interpretation of sensory information in order to represent and understand the environment (Schacter,2011;Wikipedia); an awareness of the elements of the environment through physical sensation; physical sensation interpreted in the light of experience (Merriam-Webster). This also defines hippocampusPPC-PFC function. Perception is shaped by learning, memory, expectation, and attention (Bernstein,2010;Gregory, 1987), processes which the hippocampus-PPC-PFC is engaged in (Sieb, 2013,2015). Perception also has features conditioned by the hippocampus-PPC-PFC: constancy (the ability to recognise the same event from widely varying sensory inputs-Atkinson, Atkinson \& Smith, 1990;Bernstein,2010), grouping (humans naturally perceive events as organized sets of qualia-Banerjee,1994; Goldstein,2009; Gray,2006; Weiten,1998; Wolfe et al,2008), contrast (perceived qualia can be affected by the qualities of contextCorsini,2002; Kushner,2008; Popper,2010), experience (with experience, organisms can learn to make finer perceptual distinctions and learn new kinds of categorization-Sumner,2015), motivation (Block \& Yuker,2002;Coon \& Mitterer,2008;Sieb,2013; Weiten,2010), and expectation (a predisposition to perceive things in a certain way-Coon \& Mitterer,2008; Hardy \& Heyes, 1999; Sieb,2013; Sonderegger,1998; Weiten,2010). Evolutionary psychologists hold that the primary purpose of perception is to guide action, ie. to help us move around in space (Gaulin \& McBurney, 2003). This also appears to be the purpose of the hippocampus-PPC-PFC. Reasoning (the capacity to reach novel conclusions on the basis of existing premises) is among the most complex of cognitive processes (Wendelken,2015). Prado and coworkers (2011) reported bilateral PPC activation during relational reasoning and left PPC activation during propositional reasoning. Within PPC, reasoning is most strongly associated with activation of middle to posterior IPL, and to a lesser extent, with neighboring regions of SPL (Wendelken,2015). Left PPC demonstrated greater involvement than right PPC. Wendelken and coworkers (2012) observed selectivity for higher- 
order visuospatial reasoning, but not semantic reasoning, in right PPC. There were notable similarities between reasoning activations and activations associated with visuospatial processing and attention, particularly on the right and between reasoning and phonological processing, particularly on the left. The mid-IPL appears to be unique for relational reasoning (Wendelken, 2015). Wendelken and coworkers (2012) observed stronger PPC activation for reasoning with inequalities, than for reasoning with equalities. Wendelken (2015) found that current evidence points away from logical rule-following as a primary mechanism for reasoning and is more consistent with accounts that involve estimation and probabilistic computation. He found that it was clearly indicated that the pattern of activation in $\mathrm{PPC}$ associated with reasoning is most closely related to that for mathematical cognition. Wendelken (2015) found that rostrolateral PFC extracts mental relations from the hippocampus and is specialized for second-order relational reasoning. He found that current results are consistent with the possibility that rostrolateral PFC may share this duty with a sub-region of mid-IPL. Although direct anatomical connections between rostrolateral PFC and mid-IPL have not been reported, it is noteworthy that these two regions demonstrate strong functional connectivity during task execution (Boorman et al, 2009; Wendelken, Chung \& Bunge,2012) and even at rest (Vincent et al,2008). The PPC (Berryhill \& Olson,2012) and PFC also contribute to episodic memory. In episodic memory, parietal activation is most commonly associated with the endorsement of stimuli as having been previously encountered (Nelson et al, 2013; Wagner et al,2005), though associations with memory encoding (Uncapher \& Wagner, 2009) and memory confidence (Johnson, Suzuki \& Rugg, 2013) have also been noted. The PFC (particularly in the left hemisphere) is involved in the formation of new episodic memories. Patients with damage to the PFC can learn new information, but tend to do so in a disordered fashion (Janowsky, Shimamura \& Squire,1989). The lateral PFC may be essential for remembering the contextual details of episodic memory (Gabriele \& Kao,2007). The PFC may help organize information for more efficient storage or underlie semantic strategies which enhance encoding (Gabrieli, Poldrack \& 
Desmond,1998). Causal inference is a fundamental component of cognition and perception, binding together conceptual

categories, imposing structures on perceived events, and guiding decision-making (Cummins,2014). As has been seen, the

hippocampus-PPC-PFC is involved in causal inference. Hence the hippocampus-PPC-PFC may influence perception and cognition in a number of ways.

\section{Working Memory}

Working memory is the holding in mind of multiple pieces of information for a brief period of time and its manipulation (Baddeley,2003; Cowan, 2001,2008; Fuster,1997; Hulme et al,1995; Schacter,2009). The PFC, PPC, thalamus, and parts of the basal ganglia (caudate, globus pallidus) are crucial for working memory function (Arnsten et al,2010;Ashby et al,2005; Benton, 1991 ; Fuster, 1997,2000,2008; Goldman-Rakic,1990,1995; Joseph, 2000 ; Prinz, 2003; Robbins \& Arnsten, 2009; Smith \& Jonides, 1999; Smith et al, 1998). There is an emerging consensus that most working memory tasks recruit a network of prefrontal and parietal cortical areas. Honey and coworkers (2002) have shown that the connectivity between these areas increases during a working memory task. Mottaghy (2006) demonstrated that these areas are necessary for working memory function and are not simply activated accidentally. Goldman-Rakic (1995) and Rao and coworkers (2000) showed that the dorsolateral PFC interconnects with all these brain regions and that neuronal microcircuits within the PFC are able to maintain information in working memory through recurrent excitatory (positive feedback) glutamate networks of pyramidal cells that continue to fire throughout a working memory period. The PPC is bilaterally involved in the maintenance of working memory (Wendelken,2015). PPC, and in particular SPL, has also been implicated in manipulation of the contents of working memory (Marshuetz et al, 2000; Wager \& Smith,2003; Wendelken, Bunge \& Carter,2008). The PFC may influence working memory by controlling attention, selecting strategies, and manipulating information, but not in maintenance (maintenance is attributed to more posterior areas of the brain-Curtis \& D'Esposito,2003; Postle,2006). Research suggests a close link between working memory capacity and the ability to control the information from the environment that can be attended to (Fukuda \& Vogel,2009). The goal-directing of attention is driven by "top-down" signals from the PFC that bias processing in posterior cortical areas (Desimone \& Duncan,1995) and saliency capture by "bottom-up" control from subcortical structures and the primary sensory cortices (Yantis \& Jonides, 
1990). The ability to override saliency capture differs greatly between individuals and closely links to their working memory capacity. The greater a person's working memory capacity, the greater their ability to resist saliency capture (Fukuda \& Vogel, 2009). The PFC has been found to be active in a variety of tasks that require executive function (Cavanagh, ZambranoVazquez \& Allen,2012; Kane \& Engle,2002). Executive function is the control of cognitive processing (Alvarez \& Emory,2006; Chan et al,2008; Elliott,2003; Monsell,2003). Working memory has been linked to attention, learning, cognitive development, cognitive function, and memory (Alloway \& Alloway, 2010; Andrews \& Halford, 2002;Berry et al,2009;Case, 1985; Cowan \& Alloway, 2008; Fuster, 1997,2000,2008; Jarrold \& Bayliss,2007;Kail,2007;Klingberg, Forssberg \& Westerberg,2002; Zanto \& Gazzaley,2009). An increasing number of investigations have found that the feedback connectivity between the $\mathrm{PFC}$ and $\mathrm{PPC}$ is required for conscious experience (Avidan et al,2001;Boehler et al,2008;Crick \& Koch, 1995,2003; Demertzi, Soddu \& Laureys,2013; Fahrenfort, Scholte \& Lamme, 2007; Hudetz,2006; Imas et al,2005; Ku et al,2011; Lamme \& Roelfsema,2000; Lapitskaya et al,2013; Lee et al,2009; Ro et al, 2003;Tononi \& Koch,2008). Indications are that positive feedback is involved (Goldman-Rakic,1996; Rao et al,2000; Sieb, 2004,2013,2015). Functionally, working memory is considered the provisional retention of perceptual information for prospective action, a type of focal attention whereby perception is reorganized and rerepresented, becoming explicit, functional, and conscious (Luck \& Vogel,1997; Todd \& Marois,2004;Vogel \& Machizawa, 2004). The processing of spacetime interval inequalities by the PPC and PFC could have a significant impact in working memory.

Frontal-midline (fm) theta oscillations are of particular interest in regard to higher cognitive functions (EnriquezGeppert et al,2014). Fm-theta oscillations are recorded over fronto-medial brain regions at frequencies between 4-8 $\mathrm{Hz}$ and appear to be generated in the midcingulate cortex (MCC; Cavanagh \& Frank,2014;Mitchell et al,2008), a highly interconnected brain structure (Beckmann, Johansen-Berg \& Rushworth,2009;Vogt,2009), that is part of the superordinate cognitive control network (Niendam et al,2012). The MCC is known to be crucially involved in executive functioning (Cavanagh, Zambrano-Vazquez \& Allen, 2012), which enables goal-directed behavior (Lezak, 2012).

Increases of fm-theta power have been associated with enhanced coupling between neuronal spikes and the phase of the population theta cycle, and thus are suggested to organize neural processes during decision points where executive functioning is needed and information is integrated to inform action selection (Cavanagh \& 
Frank, 2014). Enhanced cognitive processing is accompanied with increases of fm-theta (Mitchell et al,2008), specifically in tasks involving working memory (Mitchell et al,2008) and executive functions (Nigbur, Ivanova \& Stürmer,2011). In addition, fm-theta activity has been related to efficient working memory maintenance (Toth et al,2014), and increases of fm-theta activity during task processing have been shown to predict successful behavioral performance (Sederberg et al,2003) and in conflict monitoring (Cohen \& Donner, 2013). The absence of fm-theta up-regulation, when executive functioning is required, has been reported to be associated with reduced performance (Donkers et al,2011). Hence fm-theta has been proposed as a universal mechanism for executive function with the MCC acting as hub for the integration of relevant information (Cavanagh et al,2012).

The medial septal area sends cholinergic and GABAergic fibers to all parts of the hippocampus. This plays a key role in controlling the physiological state of the hippocampus; destruction of the septal area abolishes the hippocampal theta rhythm and severely impairs certain types of memory (Winson, 1978). Neural activity in nearly every part of the hippocampal system is modulated by theta. The entorhinal cortex is no exception. Like the hippocampus, it receives cholinergic and GABAergic input from the medial septal area, the central controller of theta. Grid cells, like hippocampal place cells, show strong theta modulation (Hafting et al,2005). Grid cells from layer II of the medial entorhinal cortex resemble hippocampal place cells in that they show phase precession-that is, their spike activity advances from late to early phases of the theta cycle as an animal passes through a grid vertex. Most grid cells from layer III do not show precession, but their spike activity is largely confined to half of the theta cycle. The grid cell phase precession is not derived from the hippocampus because it continues to appear in animals whose hippocampus has been inactivated by an agonist of GABA (Hafting et al, 2008).

The theta mode appears in the hippocampus during states of active, alert behavior (especially locomotion) and also during REM sleep. When cortical desynchronization (the presence of rapid irregular low amplitude EEG activity) occurs (during active searching, orientation, maintained and selective attention, initial stages of learning, discrimination responses, initial exposure to novel stimuli), hippocampal theta appears (Buzsaki,2006; Foreman \& Stevens, 1987); that is, theta appears in the hippocampus whenever an animal is actively engaged with its 
environment. The EEG is dominated by regular waves at 4-8 $\mathrm{Hz}$, often continuing for many seconds. These reflect subthreshold membrane potentials which strongly modulate the spiking of hippocampal neurons and synchronise across the hippocampus in a travelling wave pattern (Lubenov \& Siapas, 2009).

In addition to local synchronization, oscillatory activity of distant neural structures can synchronize (Llinas, 2014).

Because brain areas are bi-directionally coupled, the connections between brain areas form feedback loops.

oscillatory activity generally arises from feedback connections that result in the synchronization of firing patterns; positive feedback loops tend to cause oscillatory activity in which

frequency is inversely related to the delay time (Bollimunta et al,2011; Llinas et al,1998; Suffczynski,2001). Oscillations from multiple cortical areas can become synchronized to form a largescale oscillating network (Brovelli et al,2004). Neural oscillations may coordinate neuronal spiking between and within brain circuits (Buzsaki,2006;Buzsáki, Logothetis \& Singer,2013) and coherent large-scale brain activity may form dynamic links between brain areas required for the integration of distributed information (Varela et al,2001). Neural oscillations may provide a linkage of neural activity with behavior and thought (Enriquez-Geppert et al,2014). Different neural oscillations may appear concurrently and interact in a hierarchical way in order to implement perception and cognition (Basar \& Guntekin, 2008; Canolty et al,2006; Fingelkurts \& Fingelkurts, 2014; Herrmann, Munk \& Engel,2004). Synchronization and neural oscillation have been linked to many cognitive functions such as information

transfer, perception, motor control, and memory (Fell \& Axmacher,2011; Fries,2005; Scnitzler \& Gross,2005). Neural oscillations have been linked to cognitive states, such as awareness and consciousness (Engle \& Singer,2001; Varela et al, 2001). Hence spacetime interval inequalities may be distributed throughout a theta-oscillating hippocampus-PPC-PFC network to condition perception, conscious experience, cognitive processing, memory, and goal-directed actions. Relativistic spacetime intervals in effect direct our conscious life.

\section{Conclusion}

Conscious experience is the direct observation of conscious events. Human conscious experience is four-dimensional. Conscious events are linked (associated) by spacetime intervals to provide a coherent conscious experience. This explains why conscious experience appears to us the way it does. Conscious 
experience is an orientation in space and time, an understanding of the position of the observer in space and time. Causality, past-future relations, perception, learning, memory, cognitive function, and goal-directed actions all evolve from fourdimensional conscious experience. Spacetime intervals in effect direct our conscious life.

A neural correlate for four-dimensional conscious experience based on spacetime intervals and modelled by Einstein's special theory of relativity has been found in the human brain. Spatial and temporal cognition implement a systematic framework for the association of events and the organization of experiences. Utilizing a reference grid set up by entorhinal cortex grid cells, the hippocampus differentially encodes key events in space and time and represents spacetime interval inequalities. The PPC and PFC extract these from the hippocampus for the organization of conscious experiences, the assessment of causality and past-future relations, perception, learning, memory, cognitive function, and implementation of goal-directed actions. This occurs via a theta oscillating hippocampus-PPCPFC network. In effect, our experiences, mental states, goals, and behaviors are bound together, significantly supporting our daily activities. The relativistic concept of four-dimensional consciousness is important as it explains how conscious events are associated to form coherent conscious experiences, why conscious experience appears to us the way it does, causality and past-future assessment, perception, learning, memory, cognitive processing, and the implementation of goal-directed actions. A conceptualization of consciousness in this manner allows consciousness to be more effectively studied and understood.

\section{References}

Ackerman, C.M. \& Courtney, S.M.(2012). Spatial relations and spatial locations are dissociated within prefrontal and parietal cortex. Journal of Neurophysiology, 108, 2419-2429.

Alloway, T.P. \& Alloway, R.G.(2010). Investigating the predictive roles of working memory and $I Q$ in academic attainment. Journal of Experimental Child Psychology, 80(2), 606-621. 
Alvarez, J.A. \& Emory, E.(2006). Executive function and the frontal lobes: A meta-analytic review. Neuropsychology

Review, 16(1), 17-42.

Amaral, D. \& Lavenex, P.(2006). Ch 3. Hippocampal Neuroanatomy. In: P.Andersen, R.Morris, D.Amaral, T.Bliss, \& J.O'Keefe, The Hippocampus Book. Oxford University Press.

Amorapanth, P.X., Widick, P. \& Chatterjee, A. (2010). The neural basis for spatial relations. Journal of Cognitive Neuroscience, 22 , 1739-1753.

Andrews, G. \& Halford, G.S.(2002). A cognitive complexity metric applied to cognitive development. Cognitive Psychology, 45(2), $153-219$.

Arnsten, A.F.T., Paspalas, C.D., Gamo, N.J. \& Wang, M. (2010). Dynamic network connectivity: A new form of neuroplasticity. Trends in Cognitive Science, 14(8), 365-375.

Ashby F.G., Ell, S.W., Valentin, V.V. \& Casale, M.B.(2005) . FROST: a distributed neurocomputational model of working memory maintenance. Journal of Cognitive Neuroscience, 17(11), 17281743 .

Atkinson, R.L., Atkinson, R.C. \& Smith, E.E.(1990). Introduction to Psychology. Harcourt Brace Jovanovich. 177-183.

Avidan, M.S., et al(2001). Prevention of intraoperative awareness in a high-risk surgical population. The New England Journal of Medicine, 865, 591-600.

Baddeley, A. (2003). Working memory: looking back and looking forward. Nature Reviews Neuroscience, 4(10), 829-839.

Banerjee, J.C.(1994). Gestalt theory of perception. Encyclopaedic Dictionary of Psychological Terms. M.D. Publications Pvt. Ltd., 107-108.

Barry, C., Lever, C., Hayman, R., Hartley, T., Burton, S., O'Keefe, J., Jeffery, K. \& Burgess, N. (2006). The boundary vector cell model of place cell firing and spatial memory. Reviews in the Neurosciences, $17(1-2), 71-97$. 
Basar, E. \& Güntekin, B. (2008). A review of brain oscillations in cognitive disorders and the role of neurotransmitters. Brain Research, 1235, 172-193.

Beckmann, M., Johansen-Berg, H. \& Rushworth, M.F.S. (2009). Connectivity-based parcellation of human cingulate cortex and its relation to functional specialization. Journal of Neuroscience, 29, 1175-1190.

Behrendt, R.P.(2013). Conscious experience and episodic memory: Hippocampus at the crossroads. Frontiers Psychology, 4, 304.

Benton, A.L.(1991). The prefrontal region: Its early history. In: H.S.Levin, H.M.Eisenberg, \& A.L.Benton (Eds.), Frontal lobe function and dysfunction, 19. New York:Oxford University Press.

Bernasconi, F., Grivel, J., Murray, M. \& Spierer, L.(2010). Interhemispheric coupling between the posterior sylvian regions impacts successful auditory temporal order judgment. Neuropsychologia, 48, 2579-2585.

Bernstein, D.A.(2010). Essentials of Psychology. Cengage Learning. 123-124.

Berry, M.V.(1989). Principles of Cosmology and Gravitation. CRC Press.

Berry, A.S., Zanto, T.P., Rutman, A.M., Clapp, W.C. \& Gazzaley, A. (2009). Practice-related improvement in working memory is modulated by changes in processing external interference. Journal of Neurophysiology, 102(3), 1779-1789.

Berryhill, M.E. \& Olson, I.R.(2012). The right parietal lobe is critical for visual working memory. Neuropsychologia, 46, 17671774 .

Binder, M. D.(2009). Encyclopedia of Neuroscience, 3166. Springer.

Block, J.R. \& Yuker, H.E.(2002). Can You Believe Your Eyes?: Over 250 Illusions and Other Visual Oddities. Robson., 173-174. 
Boehler, C.N., Schoenfeld, M.A., Heinze, H.J. \& Hopf, J.M. (2008). Rapid recurrent processing gates awareness in primary visual cortex. Proceedings of National Academy of Science USA, 105, 8742-8747.

Bollimunta, A., Mo, J., Schroeder, C.E. \& Ding, M. (2011). Neuronal mechanisms and attentional modulation of corticothalamic alpha oscillations. The Journal of Neuroscience, $31(13), 4935-4943$.

Boorman, E.D., Behrens, T.E., Woolrich, M.W. \& Rushworth, M.F. (2009). How green is the grass on the other side? Frontopolar cortex and the evidence in favor of alternative courses of action. Neuron, 62, 733-743.

Botzung, A., Denkova, E. \& Manning, L.(2008). Experiencing past and future personal events: Functional neuroimaging evidence on the neural bases of mental time travel. Brain Cognition, 66, 201-212.

Brovelli, A., Ding, M., Ledberg, A., Chen,Y., Nakamura, R. \& Bressler, S.L.(2004). Beta oscillations in a large-scale sensorimotor cortical network: Directional influences revealed by Granger causality. PNAS.org.

Brown, T.I., Ross, R.S., Keller, J.B., Hasselmo, M.E. \& Stern, C.E. (2010). Which way was I going? Contextual retrieval supports the disambiguation of well learned overlapping navigational routes. Journal of Neuroscience, 30, 7414-7422.

Bueti, D., Bahrami, B. \& Walsh, V. (2008). The sensory and association cortex in time perception. Journal of Cognitive Neuroscience, 20, 1054-1062.

Burgess, N., Becker, S., King, J.A. \& O'Keefe, J.(2001). Memory for events and their spatial context: Models and experiments. Philosophical Transactions Royal Society Lond. B Biological Science, 356, 1493-1503.

Buzsáki, G.(2006). Rhythms of the Brain. Oxford, NY: Oxford University Press. 
Buzsáki, G., Logothetis, N. \& Singer, W.(2013). Scaling brain size, keeping timing: evolutionary preservation of brain rhythms. Neuron, 80, 751-764.

Byrne, P., Becker, S. \& Burgess, N. (2007). Remembering the past and imagining the future: A neural model of spatial memory and imagery. Psychological Review, 114, 340-375.

Canolty, R.T., Edwards, E., Dalal, S.S., Soltani, M., Nagarajan, S.S., Kirsch, H.E., et al.(2006). High gamma power is phaselocked to theta oscillations in human neocortex. Science, 313, $1626-1628$.

Carlsen, J., Deolmos, J. \& Heimer, L.(1982). Tracing of two neuron pathways in the olfactory system by the aid of transneuronal degeneration: Projection to the amygdaloid body and hippocampal formation. Journal of Comparative Neurology, $208,196-208$.

Case, R.(1985). Intellectual development. Birth to adulthood. New York:Academic Press.

Cavanagh, J.F. \& Frank, M.J. (2014). Frontal theta as a mechanism for cognitive control. Trends in Cognitive Science, 18, 414-421.

Cavanagh, J.F., Zambrano-Vazquez, L. \& Allen, J.J.B. (2012) . Theta lingua franca: a common mid-frontal substrate for action monitoring processes. Psychophysiology, 49, 220-238.

Chan, R.C.K., Shum, D., Toulopoulou, T. \& Chen, E.Y.H.(2008). Assessment of executive functions: Review of instruments and identification of critical issues. Archives of Clinical Neuropsychology, $23(2), 201-216$.

Cheng, P.W.(1997). From covariation to causation: a causal power theory. Psychological Review, 104, 367-405.

Chiu, Y.C., Algase, D., Whall, A., et al.(2004). Getting lost: Directed attention and executive functions in early Alzheimer's disease patients. Dementia Geriatric Cognitive Disorders, 17(3), $174-80$.

Clark, R.E., Broadbent, N.J., \& Squire, L.R.(2005). Hippocampus and remote spatial memory in rats. Hippocampus, 15(2), 260-272. 
Cohen Kadosh, R., Henik, A., Rubinsten, O., Mohr, H., Dori, H., van de Ven, V., et al.(2005). Are numbers special? The comparison systems of the human brain investigated by fMRI. Neuropsychologia, 43, 1238-1248.

Cohen, M.X. \& Donner, T.H. (2013). Midfrontal conflict-related theta-band power reflects neural oscillations that predict behavior. Journal of Neurophysiology, 110, 2752-2763.

Coon, D. \& Mitterer, J.O.(2008). Introduction to Psychology: Gateways to Mind and Behavior. Cengage Learning., 171-172.

Corsini, R.J.(2002). The Dictionary of Psychology. Psychology Press, 219.

Cowan, N. (2001). The magical number 4 in short-term memory: A reconsideration of mental storage capacity. Behavioral and Brain Sciences, 24, 87-185.

Cowan, N.(2008). What are the differences between long-term, short-term, and working memory? Progress in Brain Research, $169(169), 323-338$.

Cowan, N. \& Alloway, T.P.(2008). The development of working memory. In: N. Cowan (Ed). Development of Memory in Childhood, 2nd edition, pp. 303-342. Hove, England: Psychology Press

Crick, F. \& Koch, C.(1995). Are we aware of neural activity in primary visual cortex? Nature, 375, 121-123.

Crick, F. \& Koch, C.(2003). A framework for consciousness. Nature Neuroscience, 6(2), 119-126.

Cummins, D.D.(1995). Naive theories and causal deduction. Memory \& Cognition, 23, 646-658.

Cummins, D.D. (1997). Reply to Fairley and Manktelow's comment on "Nä̈ve theories and causal deduction". Memory \& Cognition, 25, $415-416$.

Cummins, D.D.(2014). The impact of disablers on predictive inference. Journal of Experimental Psychology: Learning, Memory, \& Cognition, 40, 1638-1655. 
Cummins, D.D.(2014). Neural correlates of causal power

judgments. Frontiers of Human Neuroscience, 8, 1014.

Cummins, D.D., Lubart, T., Alksnis, O., \& Rist, R. (1991).

Conditional reasoning and causation. Memory \& Cognition, 19, $274-282$.

Curtis, C.E. \& D'Esposito, M. (2003). Persistent activity in the prefrontal cortex during working memory. Trends in Cognitive Sciences, $7(9), 415-423$.

Das, A. (1993) The Special Theory of Relativity, A Mathematical Exposition, Springer.

Dehaene, S.(1992). Varieties of numerical abilities. Cognition, $44(1-2), 1-42$.

Dehaene, S.(1997). The number sense: How the mind creates mathematics. New York:Oxford University Press.

Dehaene, S., Piazza, M., Pinel, P. \& Cohen, L.(2003). Three parietal circuits for number processing. Cognitive Neuropsychology, 20, 487-506.

Demertzi, A., Soddu, A. \& Laureys, S.(2013). Consciousness supporting networks. Current Opinion in Neurobiology, 23 (2), 239-244.

De Neys, W., Schaeken, W., \& d'Ydewalle, G.(2002). Causal conditional reasoning and semantic memory retrieval: a test of the 'semantic memory framework'. Memory \& Cognition, 30, 908920 .

De Neys, W., Schaeken, W., \& d'Ydewalle, G.(2003). Inference suppression and semantic memory retrieval: every counterexample counts. Memory \& Cognition, 31, 581-595.

Desimone, R. \& Duncan, J.(1995). Neural mechanisms of selective visual attention. Annual Review of Neuroscience, 18, 193-222.

Dhamala, M., Assisi, C., Jirsa, V., Steinberg, F. \& Kelso, S. (2007). Multisensory integration for timing engages different brain networks. Neuroimage, 34, 764-773. 
Disalle, R. (2009) Space and Time: Inertial Frames, The Stanford Encyclopedia of Philosophy (Winter 2009 Edition), E.N. Zalta (Ed.). http://plato.stanford.edu/archives/sum2002/entries/spacetimeiframes/\#Oth

Doeller, C.F., Barry, C. \& Burgess, N. (2010). Evidence for grid cells in a human memory network. Nature, 463(7281), 657-661. Donkers, F.C.L., Schwikert, S.R., Evans, A.M., Cleary, K.M., Perkins, D.O. \& Belger, A.(2011). Impaired neural synchrony in the theta frequency range in adolescents at familial risk for schizophrenia. Frontiers of Psychiatry, 2, 51.

Eichenbaum, H. (2014). Time cells in the hippocampus: a new dimension for mapping memories. Nature Reviews Neuroscience, 15, 732-744.

Einstein, E.(2001). Relativity: The Special and the General Theory (Reprint of 1920 translation by Robert W. Lawson ed.). New York: Routledge.

Ekstrom, E.D., Kahana, M.J., Caplan, J.B., Fields, T.A., Isham, E.A., Newman, E.L. \& Fried, I.(2003). Cellular networks underlying human spatial navigation, Nature, 425, 184-188.

Elliott, R. (2003). Executive functions and their disorders. British Medical Bulletin, 65, 49-59.

Ellis, G.F.R. \& Williams, R.M.(2000). Flat and curved spacetimes (2nd ed.). Oxford University Press.

Engel, A.K. \& Singer, W.(2001). Temporal binding and the neural correlates of sensory awareness. Trends in Cognitive Sciences, $5(1), 16-25$.

Enriquez-Geppert, S., Huster, R.,J., Figge, C. \& Herrmann, C.S. (2014). Self-regulation of frontal-midline theta facilitates memory updating and mental set shifting. Frontiers of Behavioral Neuroscience, 8, 420.

Evans, B.M.(2003). Sleep, consciousness and the spontaneous and evoked electrical activity of the brain. Is there a cortical integrating mechanism? Neurophysiologie Clinique, 33, 1-10. 
Fahrenfort, J.J., Scholte, H.S. \& Lamme, V.A. (2007). Masking disrupts reentrant processing in human visual cortex. Journal of Cognitive Neuroscience, 19, 1488-1497.

Fell, J. \& Axmacher, N.(2011). The role of phase synchronization in memory processes. Nature Reviews Neuroscience, 12 (2), 105118 .

Ferbinteanu, J. \& Shapiro, M.L.(2003). Prospective and retrospective memory coding in the hippocampus. Neuron, 40, $1227-1239$.

Feynman, R.P.(1998). Six Not-so-easy Pieces: Einstein's relativity, symmetry, and space-time (Reprint of $1995 \mathrm{ed.}$. . New York: Basic Books.

Fingelkurts, A.A. \& Fingelkurts, A.A. (2014). EEG oscillatory states: universality, uniqueness and specificity across healthynormal, altered and pathological brain conditions. PloS One, $9:$ :e87507.

Flood, D.G. \& Coleman, P.D.(1990). Hippocampal plasticity in normal aging and decreased plasticity in Alzheimer's Disease. In: J.Storm-Mathisen, J.Zimmer, \& O.T.Ottersen (Eds.), Understanding the brain through the hippocampus, Progress in Brain Research, 83, 435-444.

Fonlupt, P.(2003). Perception and judgement of physical causality involve different brain structures. Cognitive Brain Research, 17, 248-254.

Foreman, N. \& Stevens, R.(1987). Relationships between the superior colliculus and hippocampus: Neural and behavioral considerations. Behavioral and Brain Sciences, 10, 101-152.

Frank, L.M., Brown, E.N. \& Wilson, M.(2000). Trajectory encoding in the hippocampus and entorhinal cortex. Neuron, 27, 169-178.

Friedman, Y.(2004). Physical Applications of Homogeneous Balls. Progress in Mathematical Physics, 40, 1-21.

Fries, P.(2005). A mechanism for cognitive dynamics: neuronal communication through neuronal coherence. TICS, 9(10), 474-480. 
Fugelsang, J.A., Roser, M.E., Corballis, P.M., Gazzaniga, M.S., \& Dunbar, K.N.(2005). Brain mechanisms underlying perceptual causality. Cognitive Brain Research, 24, 41-47.

Fukuda, K. \& Vogel, E.K.(2009). Human variation in overriding attentional capture. The Journal of Neuroscience, 29(27), 87268733 .

Fuster, J.M.(1997). The Prefrontal Cortex. Anatomy, Physiology, and Neuropsychology of the Frontal Lobe, 3rd ed, New York:

Lippincott-Raven.

Fuster, J.M.(2000). Cross-modal and cross-temporal association in neurons of frontal cortex. Nature, 405, 347-351.

Fuster, J.M. (2008). The Prefrontal Cortex, 45th ed, London: Academic Press.

Fyhn, M., Hafting, T., Witter, M.P., Moser, E.I. \& Moser, M.B. (2008). Grid cells in mice. Hippocampus, 18 (12), 1230-1238.

Gabrieli, J.D. \& Kao, Y.(2007). Development of the declarative memory system in the human brain. Nature Neuroscience, 10, 11981205 .

Gabrieli, J.D., Poldrack \& Desmond, J.E.(1998). The role of left prefrontal cortex in language and memory. Proceedings National Academy of Science U.S.A., 95(3), 906-913.

Gaulin, S.J.C. \& McBurney, D.H. (2003). Evolutionary Psychology. Prentice Hall., Chapter 4, 81-101.

Giulini, D. (2006). Algebraic and geometric structures in special relativity. In: J.Ehlers \& C.Lämmerzahl (Eds.), Special Relativity-Will it Survive the Next 101 Years? pp.45-111, Berlin: Springer.

Goldman-Rakic, P.S.(1990). Cellular and circuit basis of working memory in prefrontal cortex of nonhuman primates. In H.B.M.Uylings, C.G.Van Eden, J.P.E.DeBruin, M.A.Corner, \& M.G.P.Feenstra (Eds.), The prefrontal cortex, Progress in Brain Research, 85, 325-336. 
Goldman-Rakic, P.S.(1995). Cellular basis of working memory. Neuron, 14, 447-485.

Goldstein, E.B.(2009). Sensation and Perception. Cengage Learning.

Gray, P.O.(2006). Psychology, 5th ed., New York:Worth, 281.

Gregory, R.L. \& Zangwill, O.L.(1987). The Oxford Companion to the Mind. Oxford University Press.

Hafting, T., Fyhn, M., Bonnevie, T., Moser, M.B. \& Moser, E.I. (2008). Hippocampus-independent phase precession in entorhinal grid cells. Nature, 453 (7199), 1248-1252.

Hafting, T., Fyhn, M., Molden, S., Moser, M.-B. \& Moser, E.I. (2005). Microstructure of a spatial map in the entorhinal cortex. Nature, 436(7052), 801-806.

Hales, J.B. \& Brewer, J.B.(2010). Activity in the hippocampus and neocortical working memory regions predicts successful associative memory for temporally discontiguous events. Neuropsychologia, 48, 3351-3359.

Hales, J.B., Israel, S.L., Swann, N.C. \& Brewer, J.B. (2009). Dissociation of frontal and medial temporal lobe activity in maintenance and binding of sequentially presented paired associates. Journal of Cognitive Neuroscience, 21, 1244-1254.

Hannaman, R.A.(2005). Medstudy Internal Medicine Review Core Curriculum: Neurology 11th Ed. Medstudy, (11-1)-(11-2).

Hardy, M. \& Heyes, S.(1999). Beginning Psychology. Oxford University Press., 24-27.

Herrmann, C.S., Munk, M.H.J. \& Engel, A.K.(2004). Cognitive functions of gamma-band activity: memory match and utilization. Trends in Cognitive Science, 8, 347-355. 
Hinton, S.C. \& Meck, W.H.(2004). Frontal-striatal circuitry activated by human peak-interval timing in the supra-seconds range. Brain Research Cognitive Brain Research, 21, 171-182.

Honey, G.D., Fu, C.H., Kim, J., et al.(2002). Effects of verbal working memory load on corticocortical connectivity modeled by path analysis of functional magnetic resonance imaging data. NeuroImage, $17(2), 573-82$.

Hopfinger, J.B., Woldorff, M.G., Fletcher, E.M. \& Mangun, G.R.(2001). Dissociating top-down attentional control from selective perception and action. Neuropsychologia 39, 1277-1291.

Hubbard, E.M., Piazza, M., Pinel, P. \& Dehaene, S. (2005). Interactions between number and space in parietal cortex. Nature Reviews Neuroscience, 6(1-2), 435-448.

Hudetz, A.G.(2006). Suppressing consciousness: Mechanisms of general anesthesia. Perioperative Medicine and Pain, 25(4), 196204 .

Hulme, C., Roodenrys, S., Brown, G. \& Mercer, R. (1995). The role of long-term memory mechanisms in memory span. British Journal of Psychology, 86(4), 527-536.

Husain, M. \& Nachev, P.(2007). Space and the parietal cortex. Trends in Cognitive Science, 11, 30-36.

Imas, O.A., Ropella, K.M., Ward, B.D., Wood, J.D. \& Hudetz, A.G.(2005). Volatile anesthetics disrupt frontal-posterior recurrent information transfer at gamma frequencies in rats. Neuroscience Letters, $387(3)$, 145-150.

Ivry, R. \& Schlerf, J.(2008). Dedicated and intrinsic models of time perception. Trends in Cognitive Science. 12, 273-280.

Jacobs, J., Weidemann, C.T., Miller, J.F., Solway, A., Burke, J. F., Wei, X.X., Suthana, N., Sperling, M.R., Sharan, A.D., Fried, I. \& Kahana, M.J.(2013). Direct recordings of grid-like neuronal activity in human spatial navigation. Nature Neuroscience.doi:10.1038/nn.3466. 
Janowsky, J.S., Shimamura A.P. \& Squire, L.R. (1989). Source memory impairment in patients with frontal lobe lesions. Neuropsychologia, $27(8), 1043-1056$.

Janveau-Brennan, G., and Markovits, H. (1999). The development of reasoning with causal conditionals. Dev. Psychol. 35, 904911.

Jarrold, C. \& Bayliss, D.M. (2007). Variation in working memory due to typical and atypical development. In: A.R.A.Conway, C.Jarrold, M.J.Kane, A.Miyake. \& J.N.Towse (Eds.), Variation in working memory (pp. 137-161). New York:Oxford University Press.

Jeffery, K.(2007). Integration of sensory inputs to place cells: What, where, why, and how? Hippocampus, 17(9), 775-785.

Jeffery, K., Anderson, M., Hayman, R. \& Chakraborty, S. (2003). A proposed architecture for the neural representation of spatial context. Neuroscience and Behavioral Reviews, 28, 201-218.

Johnson, J.D., Suzuki,M. \& Rugg, M.D.(2013). Recollection, familiarity and content-sensitivity in lateral parietal cortex: a high-resolution fMRI study. Frontiers of Human Neuroscience, 7,219 .

Jones, R. (2013). Forming memories, one neuron at a time. Knowing Neurons.

Joseph, R.(2000). Neuropsychiatry, Neuropsychology, Clinical Neuroscience, New York:Academic Press.

Kail, R. (2007). Longitudinal evidence that increases in processing speed and working memory enhance children's reasoning. Psychological Science, 18(4), 312-313.

Kane, M.J. \& Engle, R.W.(2002). The role of prefrontal cortex in working-memory capacity, executive attention, and general fluid intelligence: An individual-differences perspective. Psychonomic Bulletin \& Review, 9(4), 637-671. 
Kavounoudias, A., Roll, J.P., Anton, J.L., Nazarian, B., Roth, M. \& Roll, R.(2008). Proprio-tactile integration for kinesthetic perception: An fMRI study. Neuropsychologia, 46, 567-575.

Killian, N.J., Jutras, M.J. \& Buffalo, E.A. (2012). A map of visual space in the primate entorhinal cortex. Nature. doi:10.1038/nature11587.

Kimura, H., Hirose, S., Kunimatsu, A., Chikazoe, J., Jimura, K., Watanabe, T., Abe, O., Ohtomo, K., Miyashita, Y. \& Konishi, S. (2010). Differential temporo-parietal cortical networks that support relational and item-based recency judgments. Neuroimage, $49,3474-3480$.

Kinomura, S., Larsson, J., Gulyas, B. \& Roland, P.E.(1996). Activation by attention of the human reticular formation and thalamic intralaminar nuclei. Science, 271(5248), 512-515.

Klingberg, T., Forssberg, H. \& Westerberg, H. (2002). Training of working memory in children with ADHD. Journal of Clinical and Experimental Neuropsychology, 24(6), 781-91.

Komorowski, R.W., Manns, J.R. \& Eichenbaum, H. (2009). Robust conjunctive item-place coding by hippocampal neurons parallels learning what happens where. Journal of Neuroscience, 29, 99189929 .

Ku, S., Lee, U., Noh, G., Jun, I. \& Mashour, G.A. (2011). Preferential inhibition of frontal-to-parietal feedback connectivity is a neurophysiologic correlate of general anesthesia in surgical patients. PLoS/One, 6(10).

Kumaran, D. \& Maguire, E.A.(2006). The dynamics of hippocampal activation during encoding of overlapping sequences. Neuron, 49, $617-629$.

Kushner, L.H.(2008). Contrast in judgments of mental health. Proquest. 1 .

Lucas, J.L. \& Hodgson, P.E.(1985). Space, Time and Causality. 
Lamme, V.A. \& Roelfsema, P.R.(2000). The distinct modes of vision offered by feedforward and recurrent processing. Trends of Neuroscience, 23, 571-579.

Lapitskaya, N., Gosseries, O., De Pasqua, V., Pederson, A.R., Nielsen, J.F., de Noordhout, A.M. \& Laureys, S.(2013). Abnormal corticospinal excitability in patients with disorders of consciousness. Brain Stimulation, preprint.

Lee, U., Kim, S., Nok, G., Choi, B., Hwang, E. \& Mashour, G. A. (2009). The directionality and functional organization of frontalparietal connectivity during consciousness and anesthesia in humans. Consciousness and Cognition, 18(4), 1069-1078.

Lehn, H., Steffenach, H.A., van Strien, N.M., Veltman, D.J., Witter, M.P. \& Håberg, A.K.(2009). A specific role of the human hippocampus in recall of temporal sequences. Journal of Neuroscience, 29, 3475-3484.

Lewis, P. \& Miall, R. (2003). Brain activation patterns during measurements of sub- and supra-second intervals. Neuropsychologia, 41, 1583-1592.

Lezak, M.D.(2012). Neuropsychological Assessment. 5th Edn. Oxford, New York: Oxford University Press.

Livesey, A., Wall, M. \& Smith, A. (2007). Time perception: manipulation of task difficulty dissociates clock functions from other cognitive demands. Neuropsychologia, 45, 321-331.

Llinás, R.R.(2014). Intrinsic electrical properties of mammalian neurons and CNS function: a historical perspective. Frontiers in Cellular Neuroscience, 8, 320.

Llinas, R., Ribary, U., Contreras, D. \& Pedroarena, C. (1998). The neuronal basis for consciousness. Philosophical Transactions of the Royal Society of London, 353(1377), 1841-1849.

Lubenov, E.V. \& Siapas, A.G. (2009). Hippocampal theta oscillations are travelling waves. Nature, 459(7246), 534. Luck, S.J. \& Vogel, E.K.(1997). The capacity of visual working memory for features and conjunctions. Nature, 390, 279-281. 
MacDonald, C.J., Lepage, K.Q., Eden, U.T. \& Eichenbaum, H. (2011). Hippocampal "time cells" bridge the gap in memory for discontiguous events. Neuron, 71, 737-749.

Maguire, E.A., Burgess, N., Donnett, J.G., Frackowiak, R.S.J., Frith, C.D. \& O'Keefe, J.(1998). Knowing where and getting there: A human navigation network. Science, 280(5365), 21-24.

Maguire, E.A., Gadian, D.G., Johnsrude, J.D., Good, C.D., Ashburner, J., Frackowiak, R.S. \& Frith, C.D.(2000). Navigationrelated structural change in the hippocampi of taxi drivers. PNAS, $97(8), 4398-4403$.

Maniadakis, M. \& Trahanias, P.(2011). Temporal cognition: A key ingredient of intelligent systems. Frontiers in Neurorobotics, 5,2 .

Manns, J.R. \& Eichenbaum, H.(2009). A cognitive map for object memory in the hippocampus. Learning and Memory, 16, 616-624. Markovits, H., Fleury, M., Quinn, S., \& Venet, M. (1998). The development of conditional reasoning and the structure of semantic memory. Child Development, 69, 742-755.

Marshall, J.C. \& Fink, G.R.(2001). Spatial cognition: where we were and where we are. Neuroimage, 14(1 Pt. 2), S2-S7.

Marshuetz, C., Smith, E.E., Jonides, J., DeGutis, J. \& Chenevert, T.L.(2000). Order information in working memory: fMRI evidence for parietal and prefrontal mechanisms. Journal of Cognitive Neuroscience, 12 (Suppl. 2), 130-144.

Matolcsi, T.(1994). Spacetime Without Reference Frames. Budapest: Academiai Kiado.

Maurer, A.P., Vanrhoads, S.R. Sutherland, G.R., Lipa, P. \& McNaughton, B.L.(2005). Self-motion and the origin of differential spatial scaling along the septo-temporal axis of the hippocampus. Hippocampus, 15(7), 841-852.

Mermin, N.D.(2005). It's About Time. Understanding Einstein's Relativity. Princeton University Press. 
Mesulam, M.M.(1981). A cortical network for directed attention and unilateral neglect. Annals of Neurology, 10, 309-325.

Mitchell, D.J., McNaughton, N., Flanagan, D. \& Kirk, I.J. (2008). Frontal-midline theta from the perspective of hippocampal "theta". Progress in Neurobiology, 86, 156-185.

Mohedano-Moriano, A., Pro-Sistiaga, P., Arroyo-Jimenez, M.M., Artacho-Perula, E., Insausti, A.M., Marcos, P., Cebada-Sanchez, S., Martinez-Ruiz, J., Munoz, M., Blaizot, X., Martinez-Marcos, A., Amaral, D.G. \& Insausti, R.(2007). Topographical and laminar distribution of cortical input to the monkey entorhinal cortex. Journal of Anatomy, 211, 250-260.

Monsell, S.(2003). Task switching. Trends in Cognitive Sciences, $7(3), 134-140$.

Morin, D.(2007). Introduction to Classical Mechanics, Cambridge University Press, Cambridge, Chapter 11, Appendix I.

Morris, R.G.M., Garrud, P., Rawlins, J.N.P. \& O'Keefe, J. (1982). Place navigation impaired in rats with hippocampal lesions. Nature, 297, 681-683.

Moser, E., Kropff, E. \& Moser, May-Britt(2008). Place cells, grid cells, and the brain's spatial representation system. Annual Review of Neuroscience, 31, 69-89.

Moser, M.B. \& Moser, E.I.(1998). Functional differentiation in the hippocampus. Hippocampus, 8(6), 608-19.

Mottaghy, F.M.(2006). Interfering with working memory in humans. Neuroscience, $139(1)$, 85-90.

Muir, G. \& Bilkey, D.K.(2001). Instability in the place field location of hippocampal place cells after lesions centered on the perirhinal cortex. The Journal of Neuroscience, 21(11), 4016-4025.

Muller, R.U.(1996). A quarter of a century of place cells. Neuron, 17, 813-822. 
Muller, R.U. \& Kubie, J.L.(1987). The effects of changes in the environment on the spatial firing of hippocampal complex-spike cells. Journal of Neuroscience, 7, 1951-1968.

Munoz-Lopez, M.M., Mohedano-Moriano, A. \& Insausti, R.(2010). Anatomical pathways for auditory memory in primates. Frontiers Neuroanatomy, $\mathbf{4}, 129$.

Nelson, S.M., McDermott, K.B., Wig, G.S., Schlaggar, B.L. \& Petersen, S.E.(2013). The critical roles of localization and physiology for understanding parietal contributions to memory retrieval. Neuroscientist, 19, 578-591.

Nieder, A. (2005). Counting on neurons: The neurobiology of numerical competence. Nature Reviews Neuroscience, 6, 177-190.

Nieder, A., Diester, I. \& Tudusciuc, O.(2006). Temporal and spatial enumeration processes in the primate parietal cortex. Science, 313, 1431-1435.

Nieder, A., Freedman, D.J. \& Miller, E.K.(2002). Representation of the quantity of visual items in the primate prefrontal cortex. Science, 297, 1708-1711.

Nieder, A. \& Miller, E.K.(2004). A parieto-frontal network for visual numerical information in the monkey. Proceedings of the National Academy of Sciences, 101, 7457-7462.

Niendam, T.A., Laird, A.R., Ray, K.L., Dean, Y.M., Glahn, D.C. \& Carter, C.S.(2012). Meta-analytic evidence for a superordinate cognitive control network subserving diverse executive functions. Cognitive, Affective, \& Behavioral Neuroscience, 12, 241-268.

Nigbur, R., Ivanova, G. \& Stürmer, B. (2011). Theta power as a marker for cognitive interference. Clinical Neurophysiology, $122,2185-2194$.

O'Keefe, D.J.(1976). Place units in the hippocampus of the freely moving rat. Experimental Neurology, 51(1), 78-109.

O'Keefe, J. \& Dostrovsky, J.(1971). The hippocampus as a spatial map. Preliminary evidence from unit activity in the freelymoving rat. Brain Research, 34(1), 171-175. 
O'Keefe, J., \& Nadel, L. (1978). The Hippocampus as a Cognitive Map. Oxford University Press.

Ono, T., Nakamura, K., Nishijo, H. \& Eifuku, S. (1993). Monkey hippocampal neurons related to spatial and nonspatial functions. Journal of Neurophysiology, 70, 1516-1529.

Parris, B.A., Kuhn, G., Mizon, G.A., Benattayallah, A. \& Hodgson, T.L.(2009). Imaging the impossible: an fMRI study of impossible causal relationships in magic tricks. Neuroimage, 45, 1033-1039.

Pearl, J.(2000). Causality. Cambridge: Cambridge University Press.

Penrose, R. (2005). The Road to Reality. London: Vintage Books.

Petkov, V.(2010). Minkowski Spacetime: A Hundred Years Later. Berlin: Springer.

Piazza, M., Izard, V., Pinel, P., Le Bihan, D. \& Dehaene, S. (2004). Tuning curves for approximate numerosity in the human intraparietal sulcus. Neuron, 44, 547-555.

Pinel, P., Dehaene, S., Riviere, D. \& Le Bihan, D. (2001). Modulation of parietal activation by semantic distance in a number comparison task. Neuroimage, 14(5), 1013-1026.

Pinel, P., Piazza, M., Le Bihan, D. \& Dehaene, S. (2004). Distributed and overlapping cerebral representations of number, size, and luminance during comparative judgments, Neuron, 41(6), 983-993.

Poisson, E.(2004), The motion of point particles in curved spacetime. Living Rev. Relativity 7, doi:10.12942/lrr-2004-6

Popper, A.N.(2010). Music Perception. Springer, 150.

Postle, B.R.(2006). Working memory as an emergent property of the mind and brain. Neuroscience, 139(1), 23-38. 
Prado, J., Chadha, A. \& Booth, J. R. (2011). The brain network for deductive reasoning: a quantitative meta-analysis of 28 neuroimaging studies. Journal of Cognitive Neuroscience, 23, 3483-3497.

Prinz, J.J.(2003). A Neurofunctional Theory of Consciousness. On his personal website.

Quirk, M.R.(1992). The positional firing properties of medial entorhinal neurons: Description and comparison with hippocampal place cells. Journal of Neuroscience, $12(5)$, 1945-1963.

Rao, S.G., Williams, G.V. \& Goldman-Rakic, P.S.(2000). Destruction and creation of spatial tuning by disinhibition: GABA(A) blockade of prefrontal cortical neurons engaged by working memory. Journal of Neuroscience, 20(1), 485-494.

Reiner, P.B.(1995). Are mesencephalic cholinergic neurons either necessary or sufficient components of the ascending reticular formation? Seminars in the Neurosciences, $7(5)$, 355-359.

Rindler, W.(2001). Relativity. Special, General and Cosmological. New York: Oxford University Press.

Ro, T., Breitmeyer, B., Burton, P., Singhal, N.S. \& Lane, D. (2003). Feedback contributions to visual awareness in human occipital cortex. Current Biology, 13(12), 1038-1041.

Robbins, T.W. \& Arnsten, A.F.(2009). The neuropsychopharmacology of fronto-executive function: monoaminergic modulation. Annual Review of Neuroscience, 32, 267-287.

Roberts, T. \& Schleif, S. (2007). What is the experimental basis of Special Relativity? Usenet Physics FAQ.

Robertson, R.G., Rolls, E.T. \& Georges-Francois, P. (1998). Spatial view cells in the primate hippocampus: Effects of removal of view details. Journal of Neurophysiology, 79, 11451156 .

Rolls, E.T.(2007). An attractor network in the hippocampus: Theory and neurophysiology. Learning and Memory, 14, 714-731. 
Rolls, E.T.(2013). The mechanisms for pattern completion and pattern separation in the hippocampus. Frontiers in systems Neuroscience, 7, 74 .

Rosenberg-Lee, M., Chang, T.T., Young, C.B., Wu, S. \& Menon, V. (2011). Functional dissociations between four basic arithmetic operations in the human posterior parietal cortex: a cytoarchitectonic mapping study. Neuropsychologia, 49, 25922608 .

Roser, M.E., Fugelsang, J.A., Dunbar, K.N., Corballis, P.M. \& Gazzaniga, M.S.(2005). Dissociating processes supporting causal Perception and causal inference in the brain. Neuropsychology, $19,591-602$.

Ross, R.S., Brown, T.I. \& Stern, C.E.(2009). The retrieval of learned sequences engages the hippocampus: evidence from fMRI. Hippocampus, 19, 790-799.

Sack, A.T.(2009). Parietal cortex and spatial cognition. Behavioral Brain Research, 202, 153-161.

Salgado, R.B.(1995). Relativity, Spacetime, Light Cone. http://physics.syr.edu/courses/modules/LIGHTCONE/lightcone.html

Sargolini, F., Fyhn, M., Hafting, T., McNaughton, B.L., Witter, M.P., Moser, M.-B. \& Moser, E.I.(2006). Conjunctive representation of position, direction, and velocity in entorhinal cortex. Science, 312 (5774), 758-762.

Satpute, A.B., Fenker, D.B., Waldmann, M.R., Tabibnia, G., Holyoak, K.J. \& Lieberman, M.D.(2005). An fMRI study of causal judgments. European Journal of Neuroscience, 22, 1233-1238.

Save, E., Nerad, L. \& Poucet, B.(2000). Contribution of multiple sensory information to place field stability in hippocampal place cells. Hippocampus, 10(1), 64-76.

Schacter, D.L.(2009-2011). PYCHOLOGY. Catherine Woods. 226. Schacter, D. (2011). Psychology. Worth Publishers. 
Schacter, D.L., Gilbert, D.T. \& Wegner, D.M. (2011). Semantic and episodic memory. Psychology, 2nd Ed., pp.240-241. New York: Worth Incorporated.

Schnitzler, A. \& Gross, J.(2005). Normal and pathological oscillatory communication in the brain. Nature Reviews Neuroscience, 6(4), 285-296.

Schutz, J.(1997) Independent Axioms for Minkowski Spacetime, New York: Addison Wesley Longman Limited.

Sederberg, P.B., Kahana, M.J., Howard, M.W., Donner, E.J. \& Madsen, J.R.(2003). Theta and gamma oscillations during encoding predict subsequent recall. Journal of Neuroscience, 23, 1080910814 .

Serino, S. \& Riva, G. (2014). What is the role of spatial processing in the decline of episodic memory in Alzheimer's disease? The "mental frame syncing" hypothesis. Frontiers of Aging Neuroscience, 6, 33.

Sieb, R.A.(2004). The emergence of consciousness. Medical Hypotheses, $63(5), 900-904$.

Sieb, R.A. (2013). The emergence of emotion. Activitas Nervosa Superior, 55(4), 115-145.

Sieb, R.A.(2015). Memory in four dimensions. In: M.Sakakibara \& I.Etsuro (Eds.), Memory Consolidation, Chapter 13, 259-313. New York: Nova Science Publishers, Inc.

Smith, E.E. \& Jonides, J.(1999). Storage and executive processes in the frontal lobes. Science, 283(5408), 1657-1661.

Smith, E.E., Jonides, J., Marshuetz, C. \& Koeppe, R.A. (1998). Components of verbal working memory: Evidence from neuroimaging. Proceedings of the National Academy of Sciences of the United States of America, $95(3)$, 876-882.

Solstad, T., Boccara, C.N., Kropff, E., Moser, M.B. \& Moser, E.I.(2008). Representation of geometric borders in the entorhinal cortex. Science, 322 (5909), 1865-1868. 
Sonderegger, T.(1998). Psychology. John Wiley and Sons., 45-46. Staresina, B.P. \& Davachi, L.(2009). Mind the gap: binding experiences across space and time in the human hippocampus. Neuron, 63, 267-276.

Steinvorth, S., Levine, B. \& Corkin, S.(2005). Medial temporal lobe structures are needed to re-experience remote autobiographical memories: evidence from H.M. and W.R. Neuropschologia, 43, 479-496.

Steriade, M. (1995). Neuromodulatory systems of the thalamus and neocortex. Seminars in the Neurosciences, 7(5), 361-370.

Steriade, M. (1996). Arousal revisiting the reticular activating system. Science, 272 (5257), 225-226.

Straube, B. \& Chatterjee, A. (2010). Space and time in perceptual causality. Frontiers of Human Neuroscience, 4-28.

Suffczynski, P., Kalitzin, S., Pfurtscheller, G. \& Lopes da Silva, F.H.(2001). Computational model of thalamo-cortical networks: dynamical control of alpha rhythms in relation to focal attention. International Journal of Psychophysiology, $43(1), 25-40$.

Straube, B., Wolk, D. \& Chatterjee, A. (2011). The role of the right parietal lobe in the perception of causality: a tDCS study. Experimental Brain Research, 215, 315-325.

Suddendorf, T., Addis, D.R. \& Corballis, M. (2009). Mental time travel and the shaping of the human mind. Philosophical Transactions Royal Society of London B Biology, 364, 1317-1324.

Sumner, Meghan. The effect of experience on the perception and representation of dialect variants. Journal of Memory and Language. Elsevier Inc., 2009.

Sutherland, R.J., Kolb, B. \& Whishaw, I.Q.(1982). Spatial mapping - definitive disruption by hippocampal or medial frontal cortical damage in the rat. Neuroscience Letters, 31(3), 271276 . 
Sutherland, R.J., Weisend, M.P., Mumby, D., et al (2001). Retrograde amnesia after hippocampal damage: Recent vs. remote memories in two tasks. Hippocampus, 11(1), 27-42.

Taube, J.S. (2007). The head direction signal: Origins and sensory-motor integration. Annual Review of Neuroscience, 30 , $181-207$.

Thompson, L.T. \& Best, P.J.(1989). Place cells and silent cells in the hippocampus of freely-behaving rats. Journal of Neuroscience, 9, 2382-2390.

Todd, J.J. \& Marois, R.(2004). Capacity limit of visual shortterm memory in human posterior parietal cortex. Nature, 428, $751-754$.

Tononi, G. \& Koch, C.(2008). The neural correlates of consciousness: An update. Annals of the New York Academy of Science, 1124, 239-261.

Tóth, B., Kardos, Z., File, B., Boha, R., Stam, C.J. \& Molnár, M. (2014). Frontal midline theta connectivity is related to efficiency of WM maintenance and is affected by aging. Neurobiology of Learning \& Memory, 114, 58-69. Tubridy, S. \& Davachi, L.(2011). Medial temporal lobe contributions to episodic sequence encoding. Cerebral Cortex, $21,272-280$.

Tulving, E.(1972). Episodic and semantic memory. E.Tulving, W.Donaldson(Eds.), Organization of Memory, New York:Academic Press, 381-403.

Tulving, E.(1983). Elements of Episodic Memory. New York: Oxford University Press.

Ullman, M.T.(2004). Contributions of memory circuits to language: The declarative/procedural model. Cognition, 92, 231270 .

Uncapher, M.R. \& Wagner, A.D. (2009). Posterior parietal cortex and episodic encoding: insights from fMRI subsequent memory effects and dual-attention theory. Neurobiology of Learning \& Memory, 91, 139-154. 
Van Hoesen, G.W. \& Hyman, B.T.(1990). Hippocampal formation: Anatomy and the patterns of pathology in Alzheimer's Disease. In: J.Storm-Mathisen, J.Zimmer, \& O.P.Ottersen (Eds.), Understanding the brain through the hippocampus, Progress in Brain Research, 83, 445-458.

van Wassenhove, V.(2009). Minding time in an amodal representational space. Philosophical Transactions of Royal Society London B Biological Science, 364, 1815-1830.

Varela, F., Lachaux, J.P., Rodriguez, E. \& Martinerie, J.(2001). The brainweb: phase synchronization and large-scale integration. Nature Reviews Neuroscience, 2(4), 229-239. Vargha-Khadem, F., Gadian, D.G., Watkins, K.E., Connelly, A., Van Paesschen, W. \& Mishkin, M. (1997). Differential effects of early hippocampal pathology on episodic and semantic memory. Science, 277 (1997), 376-380.

Vershueren, N., Schaeken, W., De Neys, W. \& d'Ydewalle, G. (2004). The difference between generating counterexamples and using them during reasoning. Quarterly Journal of Experimental Psychology, A 57A, 1285-1308.

Viard, A., Chetelat, G., Lebreton, K., Desgranges, B., Landeau, B., de La Sayette, V., Eustache, F. \& Piolino, P.(2011). Mental time travel into the past and the future in healthy aged adults: An fMRI study. Brain Cognition, 75, 1-9.

Vincent, J.L., Kahn, I., Snyder, A.Z., Raichle, M.E. \& Buckner, R.L.(2008). Evidence for a frontoparietal control system revealed by intrinsic functional connectivity. Journal of Neurophysiology, 100, 3328-3342.

Vogel, E.K. \& Machizawa, M.G.(2004). Neural activity predicts individual differences in visual working memory capacity. Nature, 428, 748-751.

Vogt, B.A.(2009). Cingulate Neurobiology and Disease. Oxford, New York: Oxford University Press.

Wager, T.D., Jonides, J. \& Reading, S.(2004). Neuroimaging studies of shifting attention: a meta-analysis. Neuroimage, 22, 1679-1693. 
Wager, T.D. \& Smith, E.E.(2003). Neuroimaging studies of working memory: a meta-analysis. Cognitive, Affective Behavioral Neuroscience, 3, 255-274.

Wagner, A.D., Shannon, B.J., Kahn, I. \& Buckner, R.L.(2005). Parietal lobe contributions to episodic memory retrieval. Trends in Cognitive Science, 9, 445-453.

Wald, R.M.(1984), General Relativity. University of Chicago Press.

http://en.wikibooks.org/wiki/Special Relativity/Spacetime\#The li ghtcone

Weiten, W.(1998). Psychology: Themes and Variations (4th ed.). Brooks/Cole Pub. Co., 144.

Weiten, W.(2010). Psychology: Themes and Variations, 8th Edition. Wadsworth/Cengage Learning.

Wendelken, C.(2015). Meta-analysis: how does posterior parietal cortex contribute to reasoning? Frontiers of Human Neuroscience, 8,1042 .

Wendelken, C. \& Bunge, S.A.(2010). Transitive inference: distinct contributions of rostrolateral prefrontal cortex and the hippocampus. Journal of Cognitive Neuroscience, 22, 837-847.

Wendelken, C., Bunge, S.A. \& Carter, C.S.(2008). Maintaining structured information: an investigation into functions of parietal and lateral prefrontal cortices. Neuropsychologia, 46, 665-678.

Wendelken, C., Chung, D. \& Bunge, S.A.(2012). Rostrolateral prefrontal cortex: domain-general or domain-sensitive? Human Brain Mapping, 33, 1952-1963.

Winson, J.(1978). Loss of hippocampal theta rhythm results in spatial memory deficit in the rat. Science, 201(4351), 160-163.

Wittmann, M.(2009). The inner sense of time. Philosophical Transactions Royal Society of London B Biological Science, 364 , 1955-1967. 
Wolfe, J.M., Kluender, K.R., Levi, D.M., Bartoshuk, L.M., Herz, R.S., Klatzky, R.L. \& Lederman, S.J.(2008). Gestalt grouping principles. Sensation and Perception (2nd ed.). Sinauer Associates. 78-80.

Woo, S.H., Kim, K.H. \& Lee, K.M. (2009). The role of the right posterior parietal cortex in temporal order judgment. Brain Cognition, 69, 337-343.

Wood, E.R., Dudchenko, P.A., Robitsek, R.J. \& Eichenbaum, H. (2000). Hippocampal neurons encode information about different types of memory episodes occurring in the same location. Neuron, $27,623-633$.

Xu, Y. \& Chun, M.M.(2006). Dissociable neural mechanisms supporting visual short-term memory for objects. Nature, 440, 91-95.

Yantis, S. \& Jonides, J.(1990). Abrupt visual onsets and selective attention: Voluntary versus automatic allocation. Journal of Experimental Psychology. Human Perception and Performance, 16(1), 121-134.

Yartsev, M.M., Witter, M.P. \& Ulanovsky, N.(2011). Grid cells without theta oscillations in the entorhinal cortex of bats. Nature, $\mathbf{4 7 9}$ (7371), 103-107.

Young, G.M. (2009). Coma. Annals of The New York Academy Of Sciences, 1157, 32-47.

Zanto, T.P. \& Gazzaley, A.(2009). Neural suppression of irrelevant information underlies optimal working memory performance. The Journal of Neuroscience, 29(10), 3059-3066.

Zhang, S. \& Manahan-Vaughn, D. (2013). Spatial olfactory learning contributes to place field formation in the hippocampus.

cerebral Cortex, $25(2), 423-432$. 